\title{
Spectral wave modelling of the extreme 2013/2014 winter storms in the North-East Atlantic
}

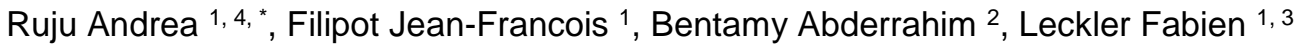

${ }_{1}^{1}$ France Energies Marines, Batiment Cap Ocean,Technopole Brest Iroise, F-29280 Plouzane, France.

2 Inst Francais Rech \& Exploitat Mer, Lab Oceanog Spatiale, F-29280 Plouzane, France.

${ }^{3}$ Serv Hydrograph \& Oceanog Marine, F-29200 Brest, France.

4 Univ Cagliari, Dept Chem \& Geol Sci, I-09042 Monserrato, Italy.

*Corresponding author : Andrea Ruju, email address : rujua@unica.it

\begin{abstract}
:
This works aims to investigate the impact of wind forcing datasets and wave breaking parameterizations on spectral wave model performance under extremely energetic conditions. For this purpose we used the wave model WaveWatch III to simulate the evolution of the highly energetic storms that occurred in winter 2013/2014 in the North-East Atlantic. We forced the wave model with two different wind datasets: one proceeding from the ECMWF ERAS reanalysis dataset and the other from satellite observations. Moreover, two wave energy dissipation parameterizations were tested: Test471 and Test500. The model accuracy was assessed by comparing the output datasets with buoy data both in deep and coastal water. Moreover, wave height measurements from satellite were used to assess the model accuracy along storm tracks across the ocean. The accuracy of simulated results shows a significant dependence on the wind forcing and wave dissipation parameterization used. Error metrics computed under storm conditions at wave buoys are consistent with those computed along storm tracks. At the wave buoy locations, all datasets tend to underestimate wave parameters at the peaks of the storms.
\end{abstract}

\section{Highlights}

- The choice of the breaking parameterization and the wind forcing affects the performance of WaveWatch III under storms. The error metrics computed under storm conditions at wave buoys are consistent with those computed along storm tracks. A significant underestimation of extreme wave conditions at the storm peak is found. The high-resolution wind forcing ERA5 does not significantly improve the error statistics computed at the wave buoys.

Keywords : Spectral wave modelling, Wind forcing, Wave energy dissipation, Wave breaking, Extreme storms, Storm tracking 


\section{Introduction}

Recent work has reported that extreme sea state conditions have increased in terms of frequency and intensity in the last decades (Young and Ribal, 2019; Reguero et al., 2018). This trend, related to climate change and possibly involved in a long-term tendency, has significance for engineering applications: among them we can mention coastal hazard assessment, offshore ship operations and the design of marine structures. Marine engineers and scientists often combine datasets proceeding from different sources in an effort to achieve an accurate and exhaustive description of extreme events and their impacts (O'Reilly et al., 2016; Castelle et al., 2015; Masselink et al., 2016). In this context, by integrating in situ and remote measurements, third-generation spectral wave models and their output make a fundamental contribution towards a better understanding and prediction of extreme wave events.

Third-generation spectral wave models are widely used nowadays for wave hindcast and forecast at global and regional scales (Bernier et al., 2016; Besio et al., 2016; Perez et al., 2017; Sandhya et al., 2018; Ruju et al., 2019). These models solve the wave action balance equation with a set of source terms encompassing the effects of physical processes from wave generation to dissipation (Tolman et al., 2013). Although the recent implementation of physical-based parameterizations has led to an increase of model output accuracy, simulating extreme wave events remains a challenge (van Vledder et al., 2016; Holthuijsen et al., 2012; Zieger et al., 2015; Campos et al., 2019). This is mainly due the paucity of observations available during the evolution and at the peak of extreme events with respect to moderate and more frequent conditions. As a result of the data used during the parameterization development and model calibration processes, model uncertainties are generally higher for rare wave conditions. For instance, Filipot and Ardhuin (2012) reported a deterioration of error statistics associated with different parameterizations for significant wave heights above $8 \mathrm{~m}$.

Under energetic and storm conditions characterized by large wave steepness values, the wave energy dissipation parameterization takes a key role in spectral evolution and wave growth limitation. Despite the significant attention received, it is likely to represent the least understood source term (Ardhuin et al., 2010). In addition to parameterizations, is is well acknowl- 
edged that wave model accuracy strongly depends on the accuracy of the wind forcing dataset (Stopa et al., 2016). This works aims to investigate the impact of two different wave breaking parameterizations and two wind forcing dataset under extremely energetic wave conditions. We use the third generation wave model WaveWatchIII (WWIII), version 5.16, to simulate the sequence of severe storms occurred that in the North-Est Atlantic during the winter 2013/2014.

Previous work has recognized the winter of 2013/2014 as one of the most exceptional in terms of storm sequence and intensity in the North-East Atlantic Ocean (Wadey et al., 2014; Masselink et al., 2016). Due to the relatively south paths of these extra-tropical cyclones, extreme energetic wave conditions were recorded by coastal monitoring systems of Western European countries, from Portugal to Ireland. On coastal areas, these storms drove extreme surge, runup and overtopping causing large morphological changes and strong damage to infrastructures (Castelle et al., 2015; Scott et al., 2016; Autret et al., 2016).

The two wave energy dissipation parameterizations tested in this work are Test471 and 500. They are both included in the parameterization group ST4 available in WWIII version 5.16. Moreover, we assess the impact of two wind forcing datasets. One of them is constituted by the wind analysis obtained through the use of various remotely sensed wind observations (Bentamy et al., 2019; Desbiolles et al., 2017). The other is the ERA5 reanalysis dataset (Hersbach et al., 2019). Model accuracy is assessed by comparing simulated results with the measurements from buoys located in the North-East Atlantic as well as satellite observations along storm tracks.

\section{Methods}

\subsection{Data collection and storm identification at wave buoys}

We collected in situ wave parameters from eight North-East Atlantic wave buoys belonging to different observational networks. Two of them (62163 and 62001) are offshore buoys, located in water depths exceeding $2500 \mathrm{~m}$. The other six $(62069,62103,62064,4403,5602$, DW5) are coastal buoys deployed in mean water depths ranging from 30 to $68 \mathrm{~m}$ (see Figure 1 showing the geographical setting). Table 1 lists the wave buoys with mean water depth and main wave parameters.

These buoys are exposed to a combination of long-period Atlantic swells and locally-generated wind waves. Due to the shelter offered by the sur- 


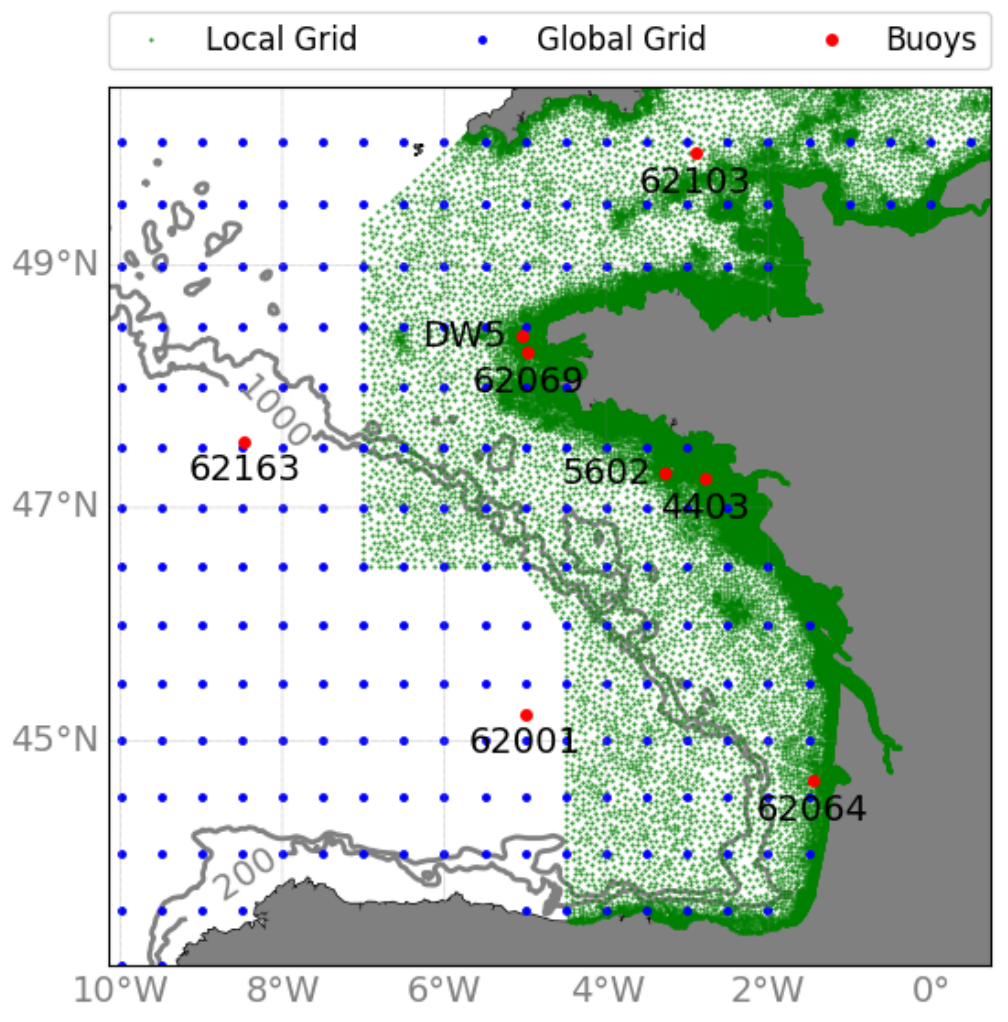

Figure 1: Global (blue dots) and local (green dots) grid configuration over the Eastern Atlantic region. Red dots indicate the buoy locations.

rounding coastline and small islands and the dissipation on the continental shelf, wave height at buoys 62103, 4403 and DW5 is significantly smaller than that at other locations. Buoy 62103 lies in the British channel and it is thus partially sheltered by the Brittany and Cornwall peninsulas. On the other hand, the presence of the islands of Ushant and Belle-Ile dampens the incoming wave energy hitting buoys DW5 and 4403, respectively. Wave propagation at coastal buoy locations is affected not only by topographic features but also by tidal dynamics (currents and water levels) that can be particularly intense in proximity of Brittany shores. All the buoys chosen in this work provide a high time coverage of nearly $100 \%$ for the winter $2013 / 2014$ on which this work focuses on. 
Table 1: Wave buoys with mean water depth and significant wave height $H_{s}$ statistics. for the period considered.

\begin{tabular}{ccccc}
\hline Buoy & depth $[\mathrm{m}]$ & mean $H_{s}[\mathrm{~m}]$ & $H_{s, 99}[\mathrm{~m}]$ & $H_{s, 70}[\mathrm{~m}]$ \\
\hline 62163 & 2526 & 5.0 & 11.9 & 5.9 \\
62001 & 4554 & 4.5 & 10.9 & 5.4 \\
62069 & 66 & 3.9 & 9.6 & 4.7 \\
62103 & 68 & 2.6 & 7.1 & 3.1 \\
62064 & 54 & 3.4 & 8.2 & 4.1 \\
4403 & 30 & 2.4 & 5.8 & 3.0 \\
5602 & 45 & 3.6 & 8.7 & 4.3 \\
DW5 & 42 & 2.5 & 6.6 & 3.0
\end{tabular}

We used the peak-over-threshold (POT) (Mathiesen et al., 1994) method to identify the 24-hour independent storms occurred during the 2013/2014 winter at buoy 62163 . The $H_{s}$ threshold was chosen equal to the $30 \%$ exceedance $H_{s}\left(H_{s, 70}\right)$ calculated over the 2013/2014 winter period. We retained only the storms with a duration larger than $12 \mathrm{~h}$ that met the independence criterium with more than 24 hours between the end of a storm and the beginning of the following one. Although the threshold value of $30 \%$ may seem low for extreme event analysis, due to the highly-energetic period considered, this method allowed the identification of 13 storms in the winter period comprised between the 21th of December and the 21th of March (dates usually taken as of the meteorological start and end of winter). However, we extended the winter period up to the 31 of March to include the 14th storm occurred on the 24th of March; see upper panel of Figure 2. The extreme wave parameters representative of each storm of the sample were selected as the values occurring at the time in which the maximum wave height was observed during the storm duration.

The adoption of the same method, used for the event identification at buoy 62163 , would have led to a different number of storms at each buoy location. For consistency, we recognized at buoys locations the same storms first identified at the offshore buoy 62163. Since this buoy lies at the westernmost location and North-East Atlantic storms are mainly moving eastward (Dodet et al., 2010), they are likely to hit first buoy 62163 and then continue propagating until they reach the other buoys. For this reason, at the other 
buoy location we expect that both the beginning and the end of a storm happen later than at buoy 62163. Therefore, we identified the beginning of a storm at each buoy location as the time at which $H_{s}$ firstly increases over $H_{s, 70}$ after the beginning of the storm at 62163 . Analogously, the end of the storm was set at the time at which $H_{s}$ falls below $H_{s, 70}$ after the end of the storm at 62163 . Note that $H_{s, 70}$ is different at each location.

The criteria of storm independence and minimal duration prescribed at buoy 62163 are not always met at the other locations. This is particularly evident at buoy 4403 where, just before the February 10th, storms S7 and S8 are contiguous since $H_{s}$ remains above the threshold for a considerable amount of time from the start of storm S7 to the end of the storm S8. Nevertheless, this procedure has the main benefit of allowing the identification of the same storms (14 in number) at each buoy location, each of them being related to the same synoptic system (see Figure 2 that highlights the storms over the time series of $H_{s}$ measured by buoys).

\subsection{Data collection and storm tracking from atmospheric pressure}

We used the fifth generation ECMWF atmospheric reanalysis ERA5 (Hersbach et al., 2019) as a database to track the low-pressure systems propagation across the Atlantic Ocean during the 2013/2014 winter. We identified the low-pressure systems from the atmospheric pressure at the sea level. First, at each ERA5 output time instant the active low-pressure systems (that we can classify as extra-tropical cyclones) were identified as those systems that have a pressure value lower than $980 \mathrm{hPA}$ and imposing a minimum distance of $5^{\circ}$ between different systems. Moreover, the evolution of system propagation in time and space was made assuming a maximum velocity of $120 \mathrm{~km} / \mathrm{h}(33.3$ $\mathrm{m} / \mathrm{s}$ ) of the low-pressure system.

This method led to the identification of a large number of low-pressure systems whose life duration spanned from few hours up to several days for the most persistent. To focus on the same events recognized at the buoy locations, we looked for the active systems at the time arrival of the 14 energetic storms, in terms of $H_{s}$, recorded at the buoy 62163. We named these low-pressure systems with the same name of the storms they drove at the buoy locations (S1, S2, etc.). Since an energetic low-pressure system drove the $H_{s}$ peak occurred in the last stage of storm S4 at buoy 62163 , we added this one (calling it S4B) to the sample constituted by the 14 systems that were active at the beginning of the 14 storms. Once identified, the propagation path of these 15 systems, responsible for the largest wave heights 


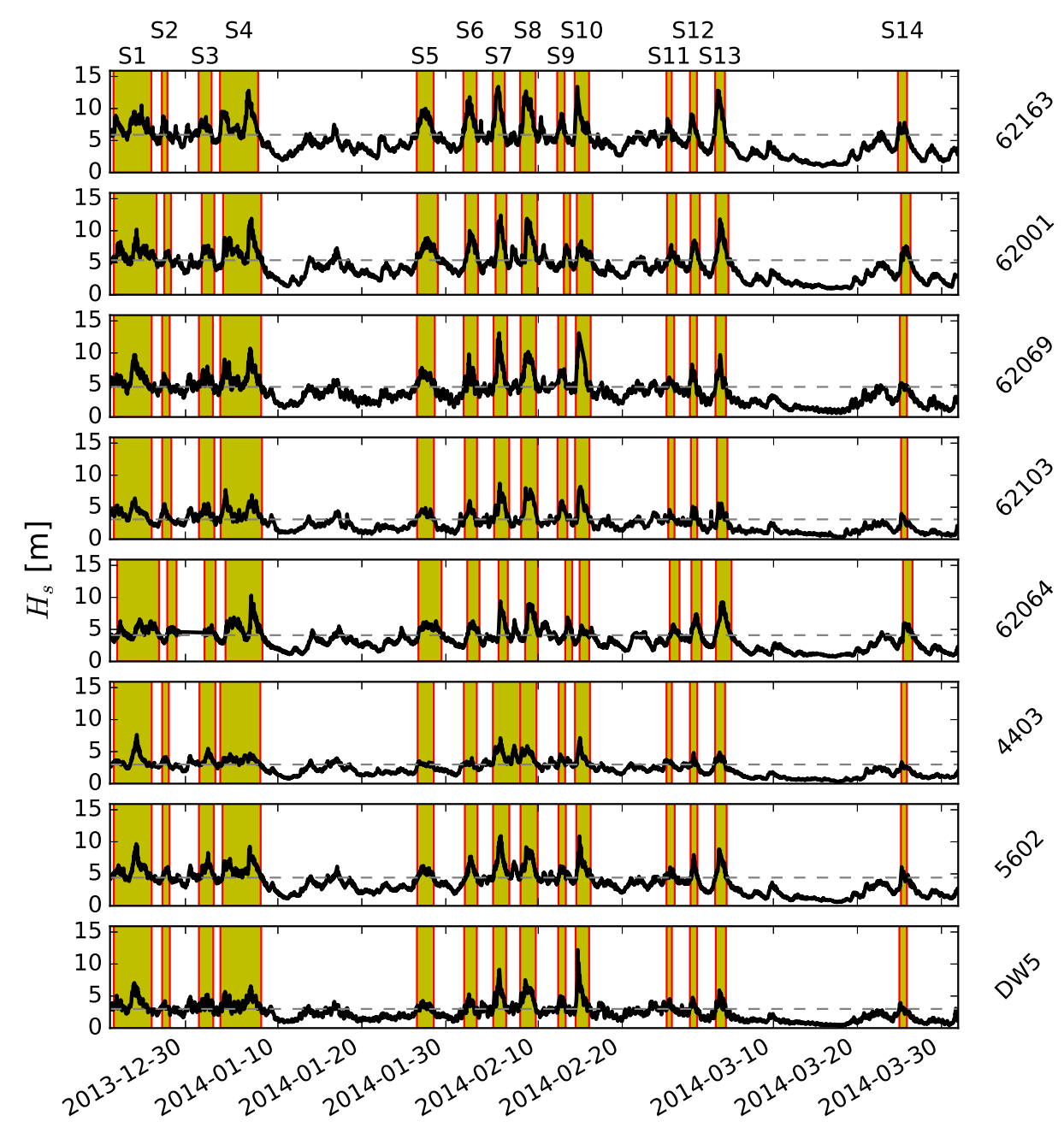

Figure 2: Time series of significant wave height $H_{s}$ at the buoy locations. Yellow rectangles extend over the storm duration. Grey dashed lines indicate the $H_{s}$ thresholds $H_{s, 70}$ used for storm identification. 
in the winter 2013/2014, was tracked back from its generation in the Western Atlantic and forward to its dissolution in the Eastern Atlantic. Figure 3 shows the paths of the low-pressure systems highlighting the intense extra-tropical cyclones driving the the five highest $H_{s}$ at the storm peak at buoy 62163 .

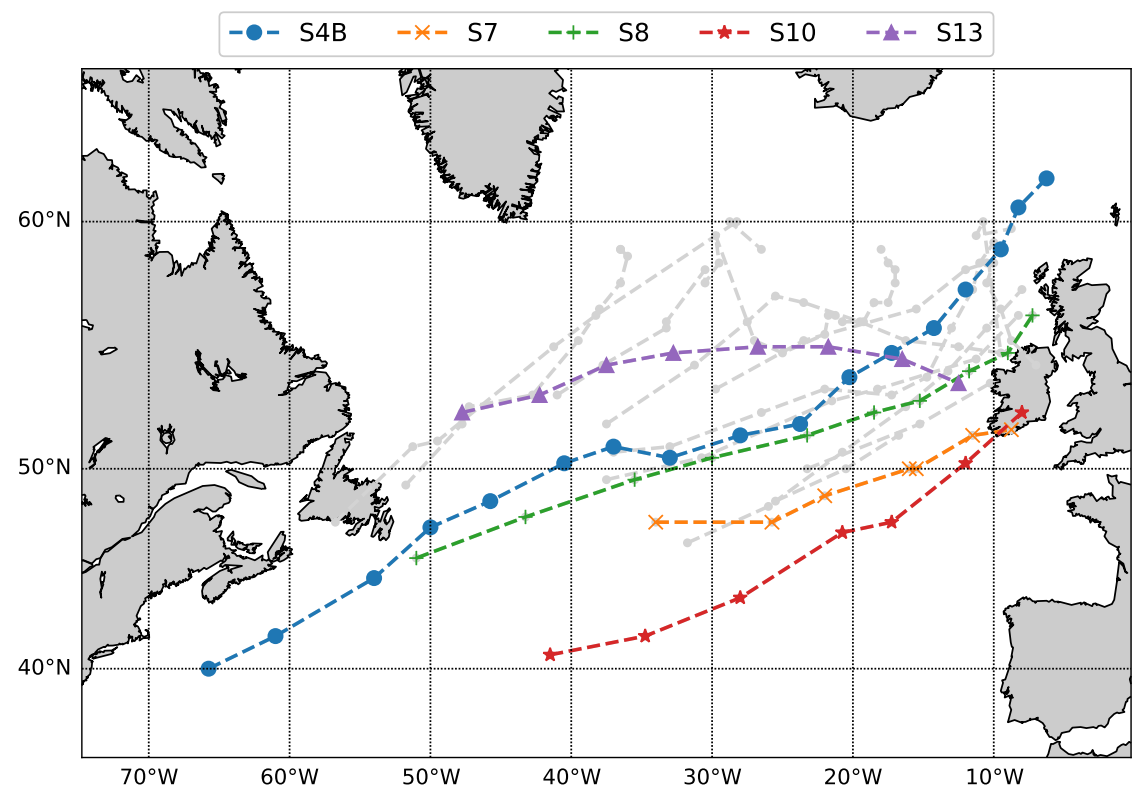

Figure 3: Paths of the low-pressure systems recorded in the winter 2013/2014 in the North Atlantic. The paths of the 5 most intense systems are highlighted by coloured lines. Markers are 6-hour spaced.

\subsection{Modelling techniques}

We used the numerical model WAVEWATCH III (WWIII) (Tolman, 2016) version 5.16 to simulate the energetic wave dynamics that occurred in the winter $2013 / 2014$. WWIII is a spectral wave model able to reproduce the physical processes governing wave motion over a wide range of water depths. Its physical and numerical configurations make it suitable to perform hindcast and forecast at global and regional scales. The governing equation of the model is the wave action balance equation in which the source and sink 
of wave energy is taken into account by means of a set of source terms:

$$
\frac{D N}{D t}=\frac{S}{\sigma},
$$

where $D / D t$ represents the total derivative (moving with a wave component) and $S$ represents the net effect of sources and sinks for the wave action spectrum $N=E / \sigma$ (where $E$ is the energy spectrum and $\sigma$ is the intrinsic frequency of the wave). Parameterizations are usually divided into four main source terms: atmospheric $S_{a t m}$, nonlinear $S_{n l}$, ocean $S_{o c}$ and bottom $S_{b t}$. This work focuses on the parameterization of wave energy dissipation by breaking included in the ocean term $S_{o c}$, that is assumed to be the most important sink of wave energy in storm seas (van Vledder et al., 2016).

In this study, a multigrid approach allowed the optimization of computational cost given the wide range of physical process scales we are focusing on: from the long scales of wave and swell generation in the deep ocean to the small scales of wave-current interaction and depth-induced processes in coastal water. The model ran over a rectangular grid with a constant spatial resolution of $0.5^{\circ}$ covering the entire globe. Wave spectra computed over this grid represented the boundary conditions for the coastal simulations performed over an unstructured grid extending over coastal water from Northern Spain in the South to the British channel in the North. This unstructured mesh was developed in the scope of the HOMONIM project, funded by the French government, in order to improve the operational wave surge forecasting system along French Altlantic coast (Michaud et al., 2015). It is made up of 92757 nodes with a decreasing resolution from $10 \mathrm{~km}$ at offshore boundaries to about $200 \mathrm{~m}$ at the coastline and is supported by an accurate and recent $100 \mathrm{~m}$ resolution bathymetry also developed in the HOMONIM project (see Biscara et al. (2014)). The triangle-based grid is used in WAVEWATCH III with the explicit N-scheme based on contour residual distribution (see Roland (2009) for a review). Initially implemented in the Wind Wave Model-II (WWM-II), this numerical scheme have then been successfully validated in WAVEWATCH III on an unstructured mesh closely similar to ours (Ardhuin et al., 2009; Boudiere et al., 2013). See figure 1 that shows the model grid configuration together with the location of the buoys. It is worth mentioning that, the mean water depths of 4 coastal buoys given in table 1 are between the minimum and maximum water depths extracted from the model simulations, as expected. The exceptions are buoys 5602 and 4403 whose mean water depth provided by the responsible entity (CEREMA 
in this case) is smaller than the depth ranges from the model: water depth ranges $56-61 \mathrm{~m}$ at 5602 and $35-41 \mathrm{~m}$ at 4403 .

We discretized the WWIII wave spectra into 32 frequencies and 24 directions. The frequency range extended from 0.0373 to $0.716 \mathrm{~Hz}$, with a frequency increment factor of 1.1. Wave directions were linearly spaced resulting in an angular resolution of $15^{\circ}$. Resonant nonlinear wave-wave interactions occurring between four wave components (quadruplets) were computed with the Discrete Interaction Approximation (DIA) method. Triad wave interactions, accounting for nonlinear energy transfer in the nearshore, were also included through the LTA model. Wave dissipation was simulated with the parameterizations of Ardhuin et al. (2010) and Filipot and Ardhuin (2012) in Test471 and Test500, respectively (see section 2.4). Table 2 lists the parameterizations used for the main source terms, see the WWIII manual (Tolman, 2016) for an exhaustive description of these terms. Note that both Test471 and Test500 are included in parameterization group ST4.

Table 2: Source term treatment in WWIII.

\begin{tabular}{ccccccc}
\hline & $\boldsymbol{S}_{\boldsymbol{i n}}+\boldsymbol{S}_{\boldsymbol{d} \boldsymbol{s}}$ & $\boldsymbol{S}_{\boldsymbol{n} \boldsymbol{l}}$ & $\boldsymbol{S}_{\boldsymbol{t r}}$ & $\boldsymbol{S}_{\boldsymbol{b o t}}$ & $\boldsymbol{S}_{\boldsymbol{d} \boldsymbol{b}}$ & $\boldsymbol{S}_{\boldsymbol{b} \boldsymbol{s}}$ \\
\hline Parameterizazion & ST4 & NL1 & TR1 & BT4 & DB1 & BS1 \\
\hline
\end{tabular}

\subsection{Parameterization of the dissipation induced by wave breaking}

The two wave dissipation parameterizations assessed in this work are those by Ardhuin et al. (2010) and Filipot and Ardhuin (2012). Consistent with previous literature (Filipot and Ardhuin, 2012; Leckler et al., 2013), they are referred to as Test471 and Test500, respectively. These formulations recognize that wave energy can be dissipated by the breaking process in two ways: a spontaneous breaking in which the energy of a wave packet is dissipated by the breaking of that very wave packet and a cumulative breaking dissipation in which energy dissipation is the result of the breaking of longer waves wiping out shorter waves. Test471 and Test500 differ in the way the spontaneous breaking source term $S_{b k}$ is computed. For this reason we briefly outline here the computation process for $S_{b k}$.

\subsubsection{Test471}

Following the work of Phillips (1984), several wave parameterizations related breaking probability to spectral saturation. Ardhuin et al. (2010) (therein after ARD10) introduced a saturation-based semiempirical wave 
breaking parameterization with a larger dissipation rate in the mean wave direction, consistent with the observations of Mironov and Dulov (2007). The directional saturation spectrum $B^{\prime}(k, \theta)$ is defined as:

$$
B^{\prime}(k, \theta)=\int_{\theta-\Delta}^{\theta+\Delta} k^{3} \cos ^{2}\left(\theta-\theta^{\prime}\right) E\left(k, \theta^{\prime}\right) d \theta^{\prime},
$$

with $\Delta=80^{\circ}, E\left(k, \theta^{\prime}\right)$ is the frequency spectrum and $k$ is the wave number. ARD10 extrapolated the theory of Banner et al. (2000), originally formulated for dominant waves, over the entire directional spectrum to obtain the breaking probability parameterization $Q_{b}$ :

$$
Q_{b}(k, \theta)=28.16 \cdot \max \left[\sqrt{B^{\prime}(k, \theta)}-\sqrt{B_{r}^{\prime}}, 0\right]^{2},
$$

where $B_{r}^{\prime}$ is the breaking threshold with a correction providing a constant ratio of the root-mean-square orbital velocity and phase speed at different water depths $d$ (Filipot et al., 2010):

$$
B_{r}^{\prime}=B_{r} Y\left(M_{4} Y^{3}+M_{3} Y^{2}+M_{2} Y+M_{1}\right),
$$

where $Y=\tanh (k d)$. The deep water threshold $B_{r}$ and the other constants in the polynomial fit can be found in ARD10. The factor 28.16 comes from the original factor of 22 of Banner et al. (2000), modified by taking into account that wave steepness is on the order of $1.6 \sqrt{B^{\prime}}$ and that the wave counting analysis for a given wave scale from Banner et al. (2000) tends to give a number of waves twice less than that expected for monochromatic waves. The dissipation term of spontaneous breaking $S_{b k}$ is:

$S_{b k}(k, \theta)=\sigma \frac{C_{d s}}{B_{r}^{\prime 2}}\left\{\delta_{d} \max \left[B(k)-B_{r}^{\prime}, 0\right]^{2}+\left(1+\delta_{d}\right) \max \left[B^{\prime}(k, \theta)-B_{r}^{\prime}, 0\right]^{2}\right\} E(k, \theta)$,

in which $C_{d s}$ is a dissipation constant, $\delta_{d}$ is a coefficient that controls the directionality of breaking and $B(k)$ is the maximum value of $B^{\prime}(k, \theta)$ for $\theta$ in the range $[0,2 \pi]$. Although this formulation is able to address both deep water and depth-induced breaking, ARD10 warned about the uncertainties involved in its application in shallow water environments.

\subsubsection{Test500}

With the main aim of overcoming the limitations of previous wave breaking parameterizations, Filipot et al. (2010) and Filipot and Ardhuin (2012) 
(therein after FAB12) made a significant effort towards a unified breaking parameterization valid from the deep ocean to the surf zone. Filipot et al. (2010) divided the frequency spectrum into wave scales with finite bandwidth centred at frequency $f_{i}$. Then, following Thornton and Guza (1983), they assumed that the breaking wave height distribution for each scale is given by the product of a Rayleigh distribution $P_{R}\left(H, f_{i}\right)$ and a weight function $W_{b}\left(H, f_{i}\right)$. In order to extend the formulation outside shallow water, they replaced the breaking criterion of Thornton and Guza (1983), based on the relative water depth $H / d$, with the breaking parameter defined by Miche (1944):

$$
\beta_{r}=\frac{\overline{k_{r}} H_{r}}{\tanh \left(\overline{k_{r}} d\right)},
$$

where $\overline{k_{r}}$ and $H_{r}$ are the representative wave number and wave height for each wave scale $f_{i}$. The breaking wave height function $W_{b}$ is:

$$
W_{b}\left(H, f_{i}\right)=1.5\left[\frac{\beta_{r}}{\beta_{t, \text { lin }}}\right]^{2}\left\{1-\exp \left[-\left(\frac{\beta}{\beta_{t, \text { lin }}}\right)^{4}\right]\right\},
$$

where $\beta_{t, l i n}$ is the breaking threshold defined by Miche (1944) but that takes into account the wave linearization (Filipot et al., 2010), inherent to the wave scale decomposition. The breaking probability for the wave scale with central frequency $f_{i}$ is:

$$
Q_{b}\left(f_{i}\right)=\int_{0}^{\infty} P_{R}\left(H, f_{i}\right) \cdot W_{b}\left(H, f_{i}\right) d H .
$$

The dissipation source term $S_{b k, i}$ for the component involved in the wave scale $i$ is then given by:

$$
S_{b k, i}(f)=\frac{D\left(f_{i}\right) E(f)}{\int_{0}^{\infty} E(f) d f},
$$

where $D\left(f_{i}\right)$ is the dissipation rate per unit area

$$
D\left(f_{i}\right)=Q_{b}\left(f_{i}\right) \Pi\left(f_{i}\right) \epsilon\left(f_{i}\right),
$$

being $\Pi\left(f_{i}\right)$ and $\epsilon\left(f_{i}\right)$ the crest length density per unit area and the dissipation rate per unit length of breaking crest, respectively (Filipot and Ardhuin, 2012). 
Since the frequency windows overlap, each spectral component is associated with several wave scales. The dissipation source term is expressed as:

$$
S_{b k}(f)=\frac{1}{N} \sum_{i=1}^{N} S_{b k, i}(f),
$$

in which $N$ is the number of wave scales involving the frequency $f$.

\subsection{Atmospheric forcings}

In this work we tested the impact of two atmospheric forcing datasets on WWIII model performance, under a winter characterized by a sequence of exceptionally energetic storm conditions in the North-East Atlantic (Masselink et al., 2016). The first forcing dataset proceeds from the wind analysis obtained through the use of various remotely sensed wind observations. On the other hand, ERA5 reanalysis represents the second forcing dataset. These forcing datasets are briefly described in the following sections.

Besides wind forcing, water levels and flow velocities computed by the Model for Applications at Regional Scales (MARS) (Lazure and Dumas, 2008) were included in the WWIII simulations. MARS simulations were carried out over three nested grids with spatial resolution ranging from $2 \mathrm{~km}$ to $250 \mathrm{~m}$ in the shallower areas. MARS output was included only in the simulations over the unstructured grid, allowing the computation of wavecurrent interactions in the coastal environment.

\subsubsection{Satellite winds}

The remotely sensed data, also referred to as satellite wind analyses, used in this study are mostly derived from scatterometer wind retrievals in combination with radiometer observations (Bentamy et al., 2019; Desbiolles et al., 2017). The main sources of remotely sensed wind data are from scatterometers onboard Metop-A (2007-present) and Metop-B (2012-present), and named ASCAT-A and ASCAT-B. Ancillary remotely sensed data are derived from radiometers Special Sensor Microwave Imager Sounder (SSMI/S) onboard the Defense Meteorological Satellite Program (DMSP) F16 (2003present) and F17 (2006-present), and from WindSat onboard Coriolis satellite (2003-present).

The scatterometer retrieval in combination with radiometer wind observations, and with the European Center of Medium Weather Forecasts (ECMWF) re-analysis model ERA Interim (Simmons et al., 2007), are used 
for determining regular in space and time surface wind analyses (Desbiolles et al., 2017). These are available at synoptic times (00h:00, 06h:00, 12h:00, and 18h:00 UTC), over the global oceans with a spatial resolution of $0.25^{\circ}$ $0.25^{\circ}$. Their accuracy, determined through comprehensive comparisons with 6-hourly averaged buoy winds, is of same order of scatterometer retrieval accuracy.

Regarding the study topic, it is of interest to determine some statistics aiming at the characterization of the remotely wind speed and direction analyses at regional scale. To achieve such purpose, satellite wind analyses are compared to collocated (in space and time) 6-hourly averaged wind speed and direction measured by buoys 62103, 62163 and 62001 (see their location in Figure 1). Scatter plots (not shown) indicate that satellite wind analyses agree well with buoy estimates for all wind speed and direction ranges, including high wind conditions. The correlation between buoy and satellite is almost 1, while symmetrical regression slope and intercept parameter are 1 and of $0.1 \mathrm{~m} / \mathrm{s}$, respectively. Furthermore, the low Root Mean Square Error RMSE values (lower than $1 \mathrm{~m} / \mathrm{s}$ and $20^{\circ}$ for wind speed and wind direction, respectively) attest the quality of satellite wind analyses. Satellite data improve the comparisons with insitu wind measurements with respect to the ERA Interim model. In fact, the satellite wind dataset contributes to reduce the bias and RMSE values, improving the comparisons for high wind conditions and confirming the results of Bentamy et al. (2017) and Desbiolles et al. (2017).

\subsubsection{ECMWF winds}

In 2018 ECMWF released the ERA5 reanalysis with spatial resolution of $0.25^{\circ}$ and 1-hour intervals (Hersbach et al., 2019). This dataset combines worldwide observations with model data collected from the 1979 until present. Atmospheric variables are given at the surface and on model levels. The variables used as forcing for the WWIII simulations in this work are the horizontal components of the wind speed at $10 \mathrm{~m}$ above the sea level (Tolman, 2016).

Although the ERA5 dataset was originally released with an hourly output resolution, we reduced the time resolution to 6-hour intervals in the WWIII forcing. This has been done with the purpose of having the two forcing datasets assessed in this study with same spatial and time resolution, thus ensuring an insightful result comparison. The influence of time resolution of forcing winds on model results will be further addressed in section 4 . 


\section{Results}

The impact of forcing winds and energy dissipation parameterizations on model performance is assessed by comparing the simulated datasets with the datasets produced by buoy and altimeter observations. Here, we adopt normalized statistics with the main aim of comparing a large range of wave conditions. The normalized root-mean-square-error NRMSE and normalized bias NBIAS are defined as follows:

$$
\begin{aligned}
\text { NRMSE } & =\sqrt{\frac{\sum\left(O_{i}-M_{i}\right)^{2}}{\sum O_{i}^{2}} .} \\
\text { NBIAS } & =\frac{\sum\left(O_{i}-M_{i}\right)}{\sum O_{i}} .
\end{aligned}
$$

where $O_{i}$ and $M_{i}$ are the observed and modelled variables.

For the sake of clarity we assign the names of each model output dataset by specifying the dissipation parameterization used followed by the wind forcing. For instance, the output including Test500 and the ECMWF forcing is called Test500ECMWF.

\subsection{Wave buoys}

Figure 4 shows the comparison between observed and modelled significant wave height $H_{s}$ time series at the offshore buoy 62163 and at the coastal buoy 5602. Despite some differences among the four model outputs, overall the WWIII datasets are able to capture the main evolution of the observed dataset. However, evident discrepancies can be found at storm peaks where the modelled $H_{s}$ underestimate the observations, especially in coastal water. An exception to this trend is represented by Test500Satellite at buoy 62163 that seems to better represent the $H_{s}$ evolution at the peak of the main storms.

To achieve a quantitative assessment of model performance, modelled time series are linearly interpolated over the observed time series. The scatterplots of the total number of samples $N$, divided into deep water and coastal water, are shown in Figure 5 , for the wave parameter $H_{s}$. NRMSE is on the order 0.1 at deep water buoy locations, ranging between 0.098 for Test500ECMWF and 0.134 for Test500Satellite. Test500Satellite slightly overestimates $H_{s}$ (NBIAS is 0.031 ), whereas a small underestimation is given 


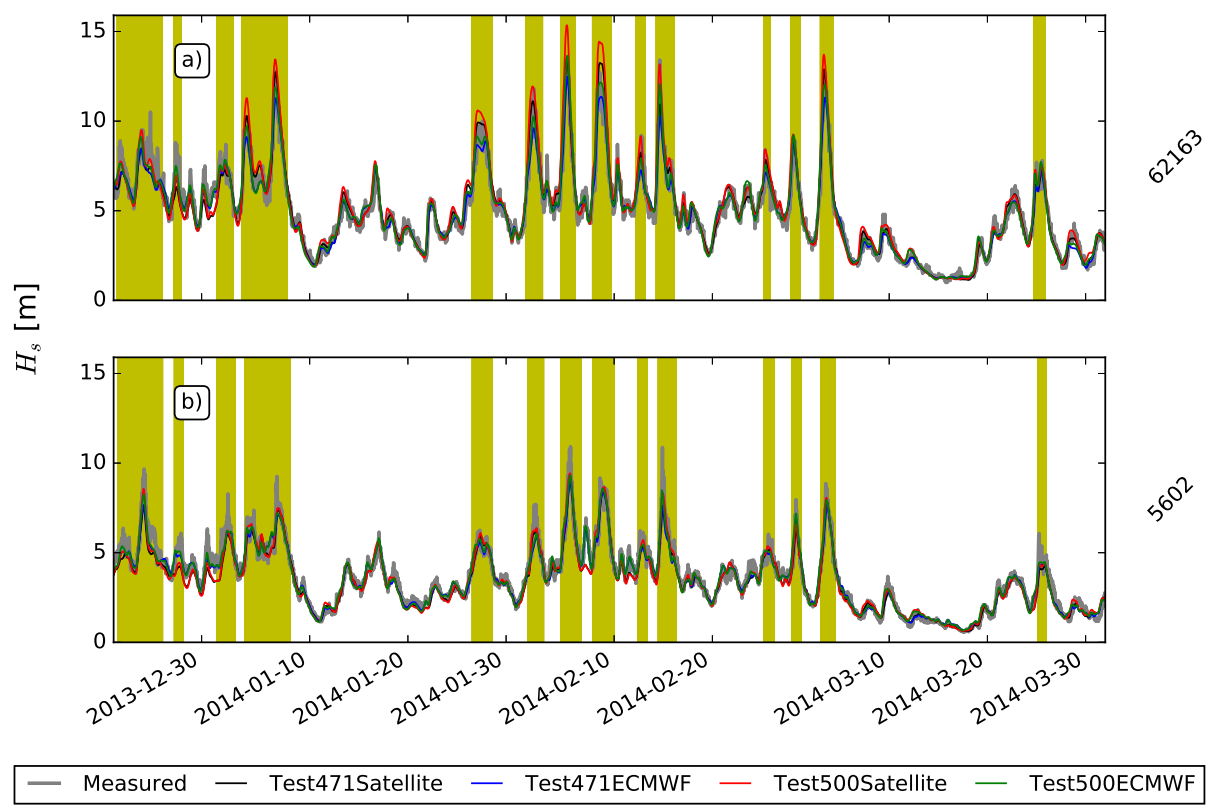

Figure 4: Observed (gray line) and predicted time series of significant wave height $H_{s}$ at the deep water buoy 62163 (a) and at the coastal buoy 5602 (b). The four computed datasets are shown. Storms are coloured in yellow.

by Test471ECMWF (NBIAS is -0.025). The other two datasets are practically unbiased $(|\mathrm{NBIAS}|<0.003)$.

In general terms, for all datasets the NRMSE of $H_{s}$ increases by few points percentage at coastal buoy locations. This is an expected result given the additional modelling challenges represented by the coastal environment (van Vledder et al., 2016), such as complex bathymetries and tidal currents, with respect to the deep ocean. A remarkable result comes from the observation of coastal water scatterplots and the associated NBIAS of $H_{s}$. In fact, whereas all datasets overestimate $H_{s}$ with positive NBIAS between 0.01 and 0.042 , the points associated to higher $H_{s}\left(H_{s}>10 \mathrm{~m}\right)$ fall below the line of perfect agreement, meaning that those large $H_{s}$ are underestimated. This is in agreement with the $H_{s}$ underestimation at storm peaks already observed in Figure 4.

The analysis of model accuracy is integrated by the Taylor diagrams in 
figure 6. All datasets have Correlation Coefficients larger than 0.95. In deep water, Test471Satellite and Test500ECMWF have the larger agreement with the observations in terms of Standard Deviation and RMSD. In coastal water, the differences between datasets are less marked, with Test500Satellite slightly improving the prediction in terms of Standard Deviation.

\subsubsection{Storm evolution and peaks}

To explore in more detail the model performance in addressing extreme $H_{s}$, Figure 7 provides the scatterplots of observed and modelled $H_{s}$ at the storm peak. In this case the number of samples $N$ is simply given by the product of the number of storms times the number of locations. For all datasets the NRMSE increases in coastal water. Moreover, NBIAS is always negative confirming the $H_{s}$ underestimation at storm peaks. Both in deep and coastal water, Test500Satellite gives the lowest NBIAS in absolute value (the underestimation is less pronounced). Whereas the largest $H_{s}$ underestimation (minimum NBIAS) is provided by Test471ECMWF.

In contrast with Figure 7, we do not observe a systematic negative NBIAS for $H_{s}$ in Figure 8. This Figure shows the scatterplots of observed and modelled $H_{s}$ collected during storms in deep water and at coastal buoy locations. In coastal water, the positive NBIAS values of datasets involving the parameterization Test500 are likely to be driven by the large number of $H_{s}$ data below $6 \mathrm{~m}$. However, underestimation is still noticeable for more energetic conditions $\left(H_{s}>6 \mathrm{~m}\right)$. Figure 10 aims at pointing out the difference between the identification of the extreme $H_{s}$ at the peak of a storm (the circle, in this case storm S10) and the identification of the $H_{s}$ values collected during a storm (the thick line). Note that the time instants at which extreme $H_{s}$ occurs for the observed and modelled dataset do not necessarily coincide. For instance, with the ECMWF and satellite datasets, the modelled maximum is slightly ahead and delayed, respectively.

The Taylor diagrams of figure 9 integrate the information provided by the scatter plots of figure 8. Correlation Coefficients are on the order of 0.9 for all datasets. In deep, Test500Satellite gives the largest Standard Deviations. In coastal water, the low values of the modelled Standard Deviations seem to confirm the peak underestimation already suggested by the scatterplots of figure 8.

Figure 11 shows the extreme wave energy flux $F_{e}$ computed at the peak of the storm and during the storm occurrence in coastal water. The wave energy flux $F_{e}$ is calculated from linear theory, assuming a Rayleigh distribution 

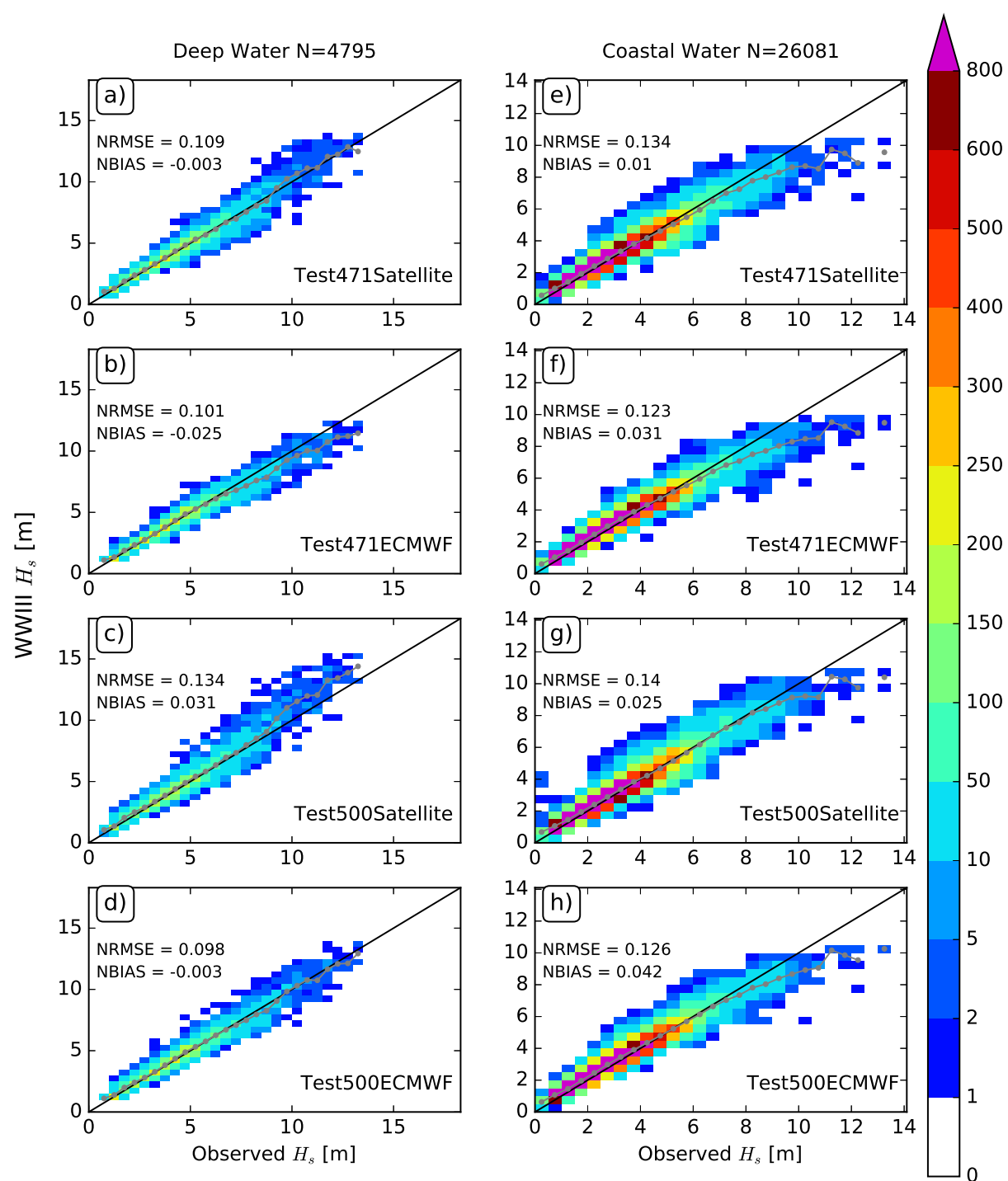

Figure 5: Scatter plot of observed versus modelled significant wave height $H_{s}$ in deep water (a-d) and coastal water (e-h). The four datasets are shown. The grey line represents the mean of the model values. 

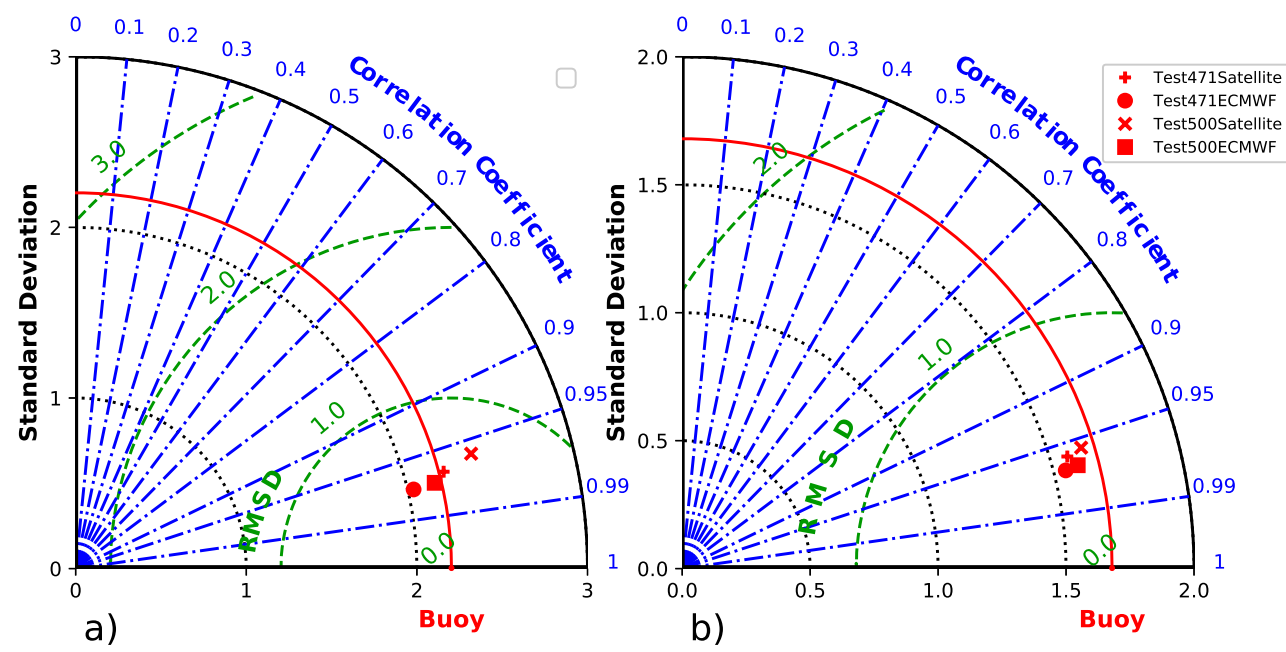

Figure 6: Taylor diagrams of Significant wave height in deep (a) and coastal (b) water.

of wave heights (Longuet-Higgins, 1952), as the product between the wave energy density $E$ and the group celerity $c_{g}$ :

$$
F_{e}=E \cdot c_{g},
$$

in which

$$
E=\frac{1}{8} \rho g H_{R M S}^{2},
$$

$$
c_{g}=\frac{1}{2} c\left(1+\frac{2 k h}{\sinh (2 k h)}\right),
$$

where $\rho$ is the water density, $g$ is the acceleration of gravity, $H_{R M S}$ is the root mean square wave height $\left(H_{R M S}=H_{s} / 1.4\right), c$ is the wave celerity, $k$ is the wave number and $h$ is the water depth. Both $c$ and $k$ are computed from linear wave theory using the mean period $T_{02} . \quad F_{e}$ plots tend to be more scattered than those of $H_{s}$, with Test471ECMWF providing the largest NRMSE for $F_{e}$ both at the peak and during the storm. Test471ECMWF also gives the largest underestimation of $F_{e}$. Test500Satellite is the only dataset that overestimates $F_{e}$ (NBIAS=0.05) during storms although, analogously the $H_{s}$ trend commented in Figure 8, large values $\left(F_{e}>0.5 \frac{\mathrm{MJ}}{\mathrm{ms}}\right)$ are clearly underestimated. This point will be discussed in section 4 . Tables 3 and 4 list the error statistics of the four datasets at the wave buoys. 
Table 3: $H_{s}$ statistics.

\begin{tabular}{cccccccc}
\hline \multirow{2}{*}{ Dataset } & \multicolumn{6}{c}{$H_{s}$ NRMSE } \\
& $\begin{array}{c}\text { Extreme } \\
\text { Deep Water }\end{array}$ & \multicolumn{4}{c}{$\begin{array}{c}\text { All Extreme } \\
\text { Coastal Water }\end{array}$} \\
\hline T471Satellite & 0.11 & 0.12 & 0.11 & 0.13 & 0.19 & 0.13 \\
T471ECMWF & 0.10 & 0.16 & 0.11 & 0.12 & 0.19 & 0.13 \\
T500Satellite & 0.13 & 0.09 & 0.14 & 0.14 & 0.16 & 0.14 \\
T500ECMWF & 0.10 & 0.11 & 0.10 & 0.13 & 0.16 & 0.13 \\
\hline \multicolumn{7}{c}{$H_{s}$ NBIAS } \\
Dataset & All Extreme & Storm & All & Extreme & Storm \\
\multicolumn{7}{c}{ Deep Water } & \multicolumn{5}{c}{ Coastal Water } \\
\hline T471Satellite & -0.00 & -0.09 & -0.01 & 0.01 & -0.12 & -0.00 \\
T471ECMWF & -0.03 & -0.15 & -0.05 & 0.03 & -0.13 & 0.00 \\
T500Satellite & 0.03 & -0.01 & 0.05 & 0.03 & -0.08 & 0.02 \\
T500ECMWF & -0.00 & -0.09 & -0.01 & 0.04 & -0.09 & 0.03 \\
\hline
\end{tabular}

Table 4: $T_{2}$ and $F_{e}$ statistics in coastal water.

\begin{tabular}{cccc|ccc}
\hline & \multicolumn{3}{c}{$T_{02}$ NRMSE } & \multicolumn{3}{c}{$F_{e}$ NRMSE } \\
Dataset & All & Extreme & Storm & All & Extreme & Storm \\
\hline T471Satellite & 0.12 & 0.11 & 0.08 & 0.33 & 0.51 & 0.34 \\
T471ECMWF & 0.09 & 0.14 & 0.08 & 0.34 & 0.55 & 0.36 \\
T500Satellite & 0.14 & 0.11 & 0.09 & 0.32 & 0.44 & 0.32 \\
T500ECMWF & 0.10 & 0.13 & 0.07 & 0.31 & 0.49 & 0.32 \\
\hline \multicolumn{3}{c}{$T_{02}$ NBIAS } & \multicolumn{4}{c}{$F_{e}$ NBIAS } \\
Dataset & All & Extreme & Storm & All & Extreme & Storm \\
\hline T471Satellite & 0.04 & -0.05 & 0.01 & -0.01 & -0.35 & -0.04 \\
T471ECMWF & -0.01 & -0.10 & -0.03 & -0.05 & -0.42 & -0.11 \\
T500Satellite & 0.06 & -0.03 & 0.03 & 0.05 & -0.27 & 0.05 \\
T500ECMWF & 0.00 & -0.08 & -0.02 & -0.01 & -0.36 & -0.05 \\
\hline
\end{tabular}



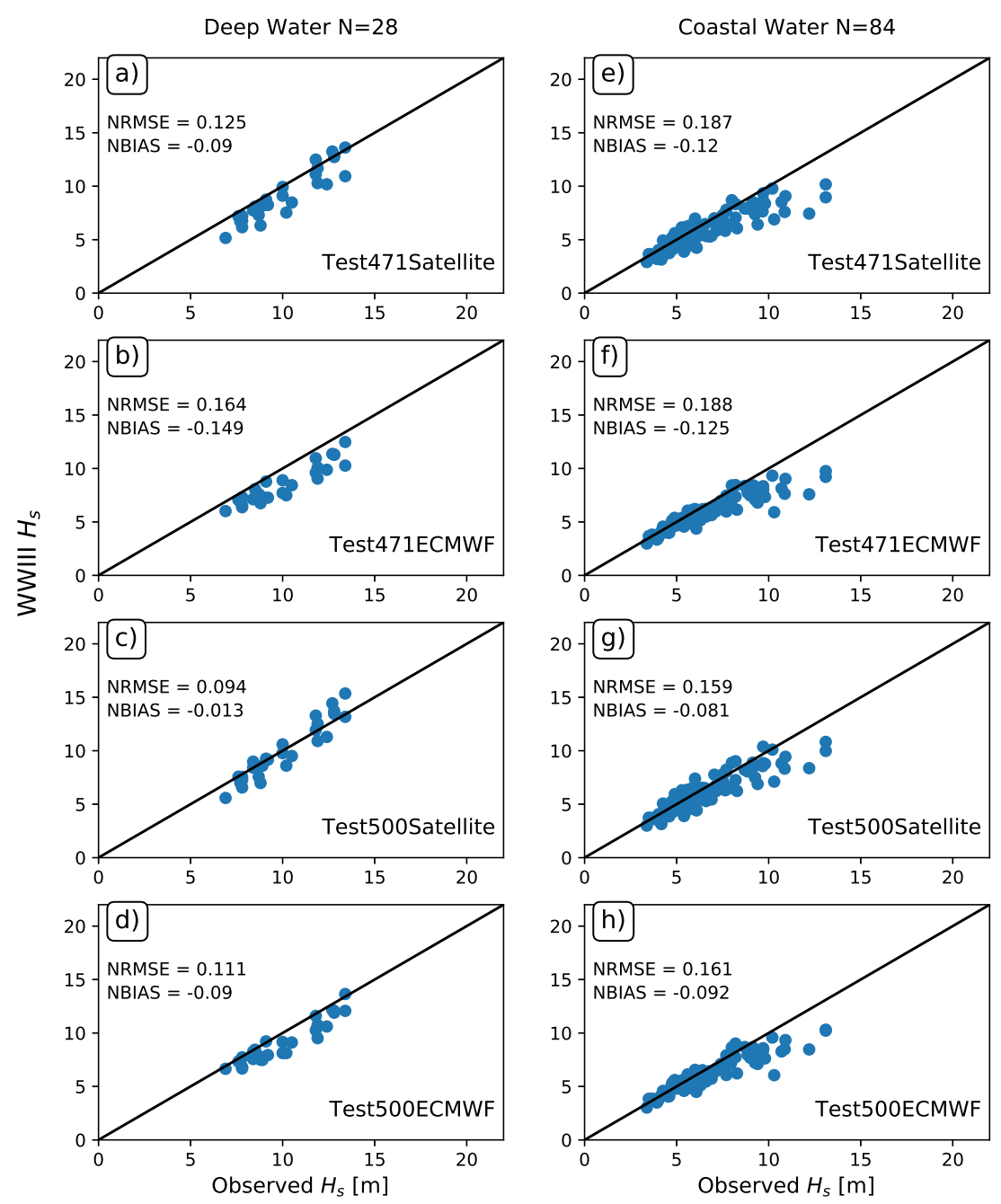

Figure 7: Scatter plot of observed versus modelled extreme significant wave height $H_{s}$ in deep water (a-d) and coastal water (e-h). The four datasets are shown.

\subsubsection{Spectral wave analysis and sea/swell decomposition}

The availability of the two-dimensional spectra at the four coastal buoys managed by CEREMA $(62069,62064,4403,5602)$ allows the spectral anal- 

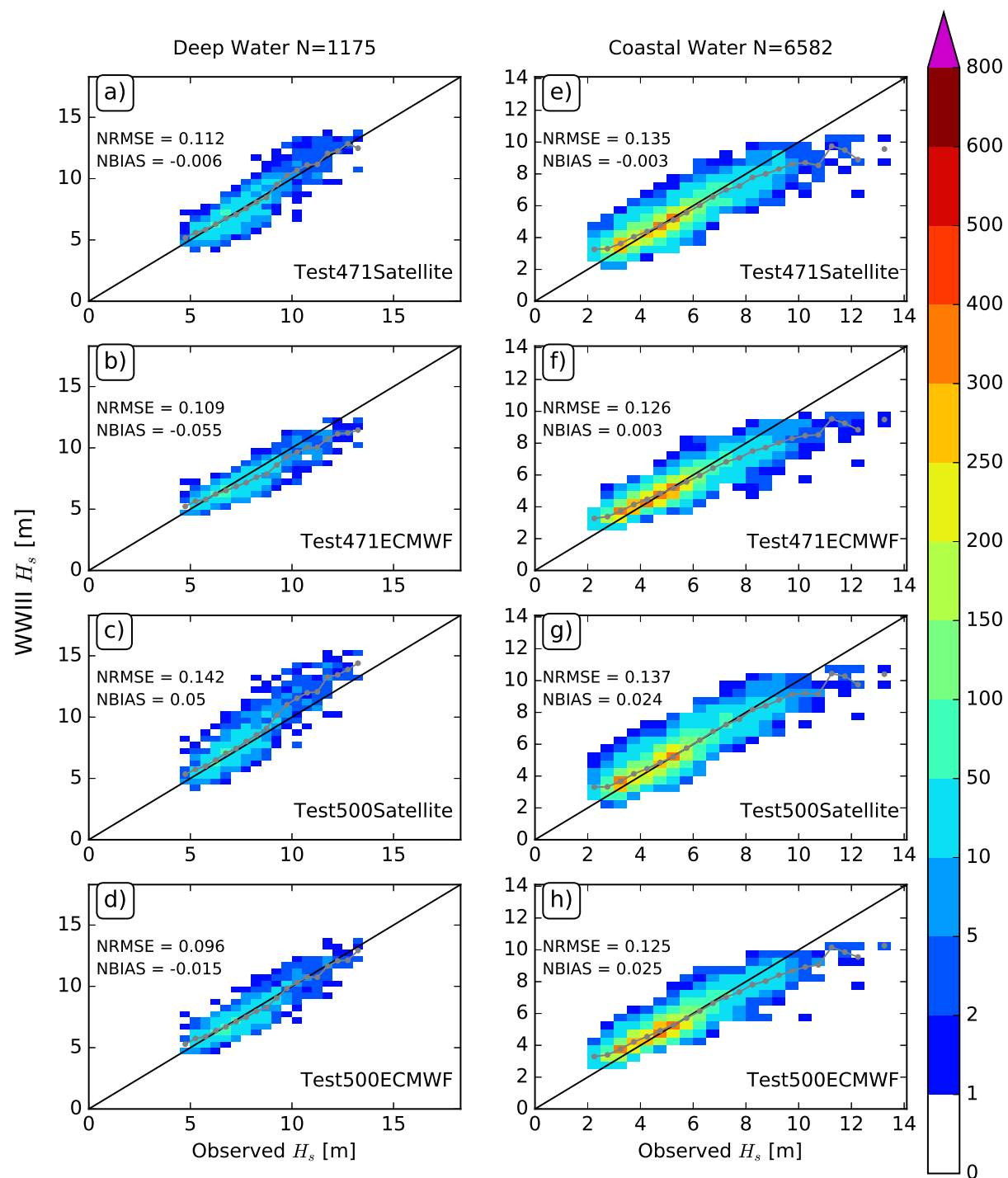

Figure 8: Scatter plot of observed versus modelled significant wave height $H_{s}$ in deep water (a-d) and in coastal water (e-h) during storm duration. The four datasets are shown. The grey line represents the mean of the model values. 

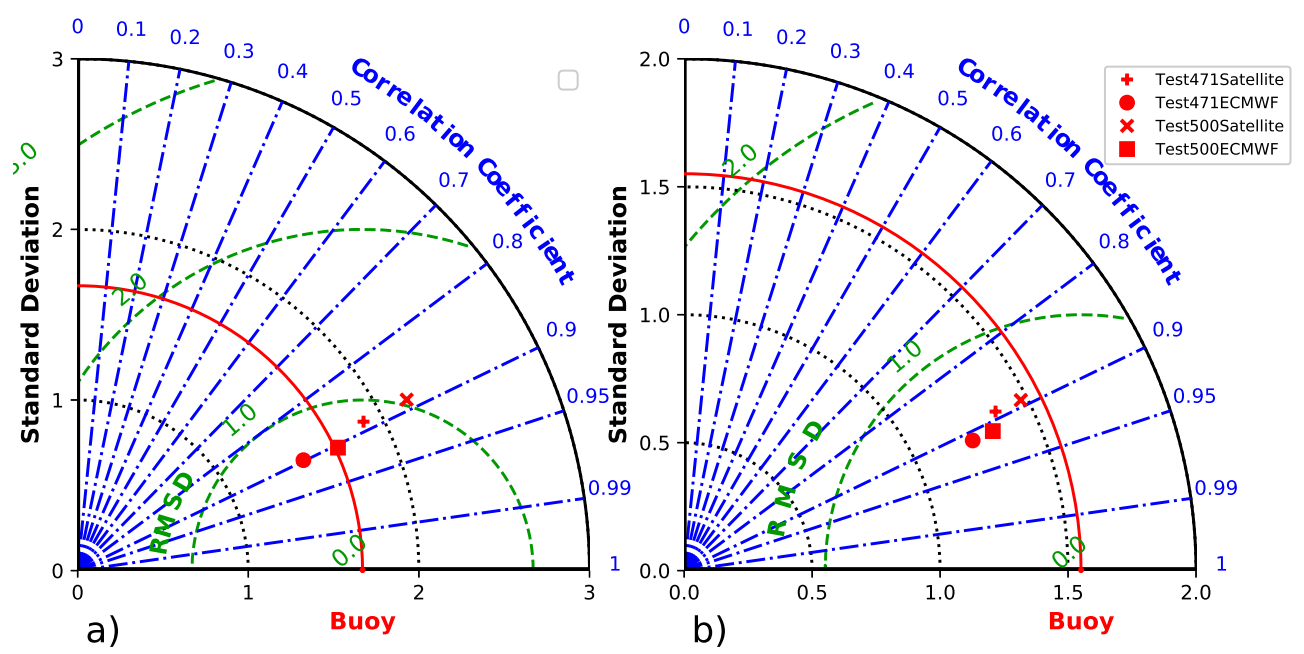

Figure 9: Taylor diagrams of significant wave height during storms in deep (a) and coastal (b) water.

ysis of storms occurred in the winter 2013/2014 at those locations. An example of spectral evolution during a storm is displayed in Figures 12 and 13 for storm S10 at the coastal buoy 62069. At the beginning of the storm, the measured spectrum shows a variegated shape with multiple peaks (see for instance the secondary peak at $0.17 \mathrm{~Hz}$ and $200^{\circ}$ ) that are less marked in the modelled spectrum (T471ECMWF). At the end of the storm, the computed spectrum reproduces the secondary peak at frequencies lower than $0.1 \mathrm{~Hz}$ and direction nearly opposite with respect to mean storm direction, probably due to wave reflection at the shoreline. Figure 13 highlights as the wide 1-D frequency spectrum observed at the beginning of the storm tends to a more narrow shape as the storm attenuates towards the end. At the peak of the storm, the energy gap between the modelled spectra and the measured one is particularly evident. At the storm beginning, both the atmospheric $S_{i n}$ and the energy dissipation $S_{d s}$ source terms proceeding from datasets using satellite forcing are larger that those of the ECMWF dataset. Moreover, Test500 seems to give a smoother dissipation spectrum. This is consistent with Leckler et al. (2013) and is likely due to the averaging over wave scales of equation (11). On the contrary, as a result of its dissipation rate that is local in frequency, Test471 gives a higher dissipation rate at the peak fre- 

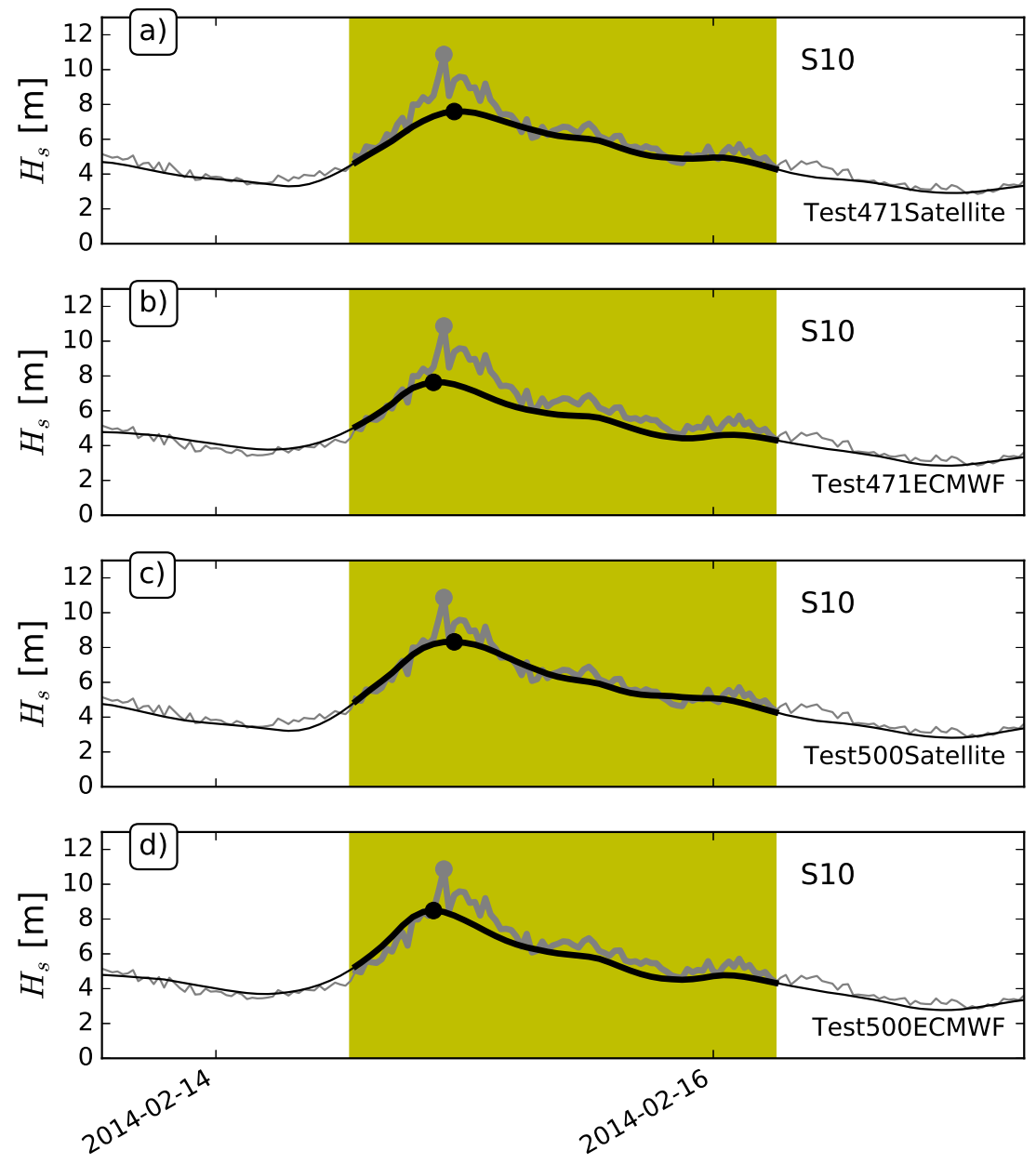

Figure 10: Observed (gray) and modelled (black) significant wave height $H_{s}$ during storm S10 at buoy 5602. Thick lines highlights the $H_{s}$ evolution during the storm. The circles indicate the extreme $H_{s}$ values. 

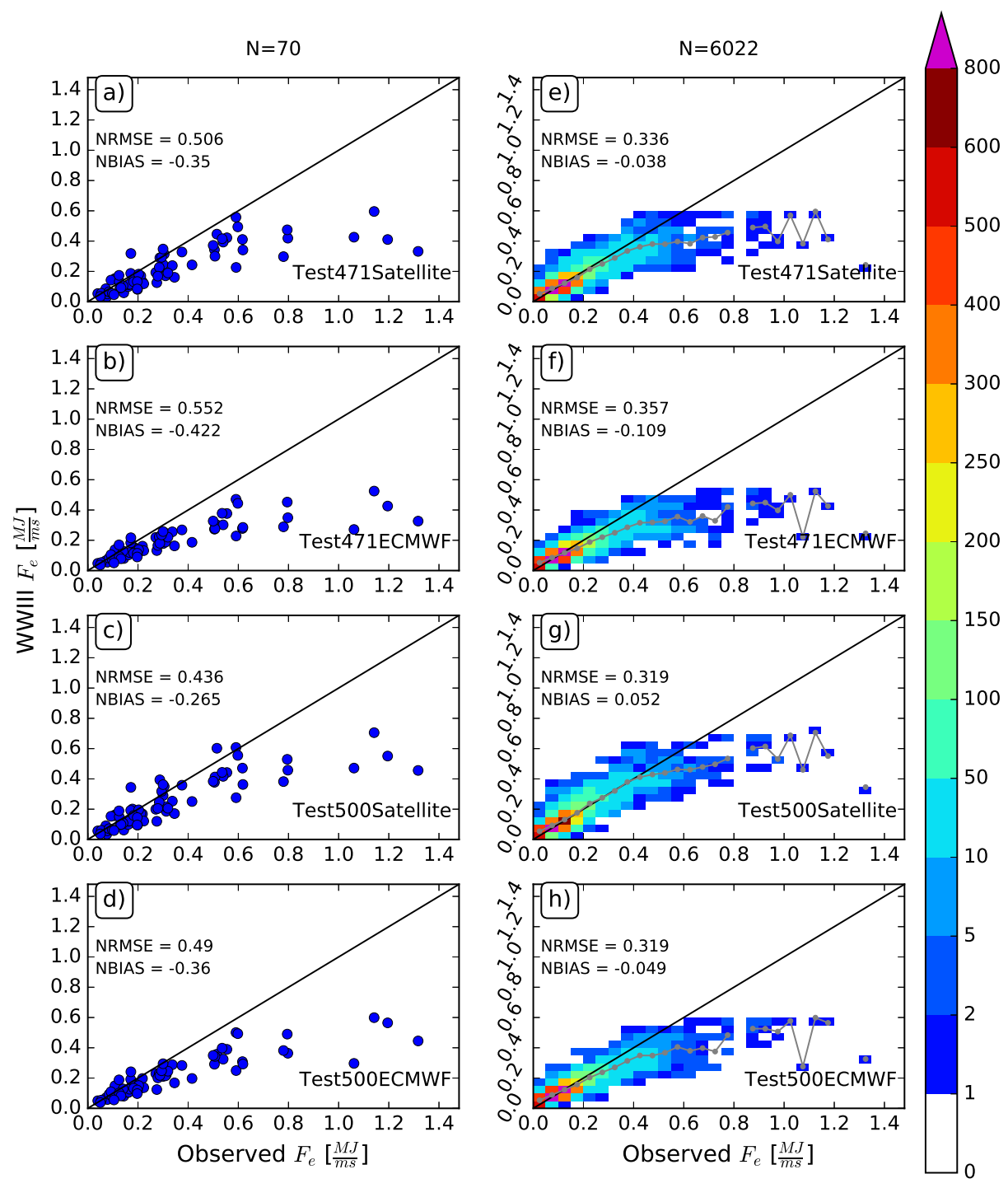

Figure 11: Scatter plot of observed versus modelled extreme (a-d) and collected during storms (e-h) energy flux $F_{e}(\mathrm{a}-\mathrm{d})$ in coastal water. The four datasets are shown. The grey line represents the mean of the model values. 
quency at the beginning and at the peak of the storm. At the end of the storm, Test500 gives the higher dissipation rates. However, their impact on storm evolution seems to be limited since these dissipation rates at the end of the storm are three orders of magnitudes smaller than those at the storm peak.

The identification of the wind and swell components of the spectrum is carried out by means of the wave age criterion first introduced by Hanson and Phillips (2001). The wind sea component $W$ is defined as:

$$
W=\left.E^{-1} E\right|_{U_{p}>c},
$$

where $E$ is the total spectral energy and $\left.E\right|_{U_{p}>c}$ is the energy of the region of the spectrum under the direct influence of the wind. $U_{p}$ is the projection of the wind speed, with direction $\theta$, along the mean wave direction $\theta_{w}$ :

$$
U_{p}=C U_{10} \cos \left(\theta-\theta_{w}\right),
$$

where $\mathrm{C}$ has been set equal to 1.7. Figure 14 shows the scatter plots of the wind and swell components of the significant wave height for the four datasets. Swell waves are characterized by a larger NRMSE than wind waves, with all the datasets that tend to underestimate extreme values larger than 6 $\mathrm{m}$. The extreme values of wind waves $(>10 \mathrm{~m})$ are larger than those of swell waves. These extreme wind wave conditions are slightly underestimated, although the ECMWF forcing leads to a positive NBIAS due to overestimation of moderate values. Table 5 reports the error statistics of the sea and swell components of the four datasets at the coastal wave buoys. It is worth noting that all datasets have, respectively, positive and negative NBIAS for wind and swell waves under storm duration. Therefore, the virtually unbiased total $H_{s}$ values during storms may be the result of a balance between a small overestimation of the wind component combined with a small underestimation of the swell component.

\subsection{Storm tracking}

Figure 15 shows the result of the storm tracking process for storm S10. The storm path from its generation to its dissipation is superposed to the atmospheric pressure field at the time of storm arrival at buoy 62163 (see Figure 15b). The centre of the low pressure system lies few hundreds $\mathrm{km}$ west of the buoy. The large pressure gradients in the southern part of the 

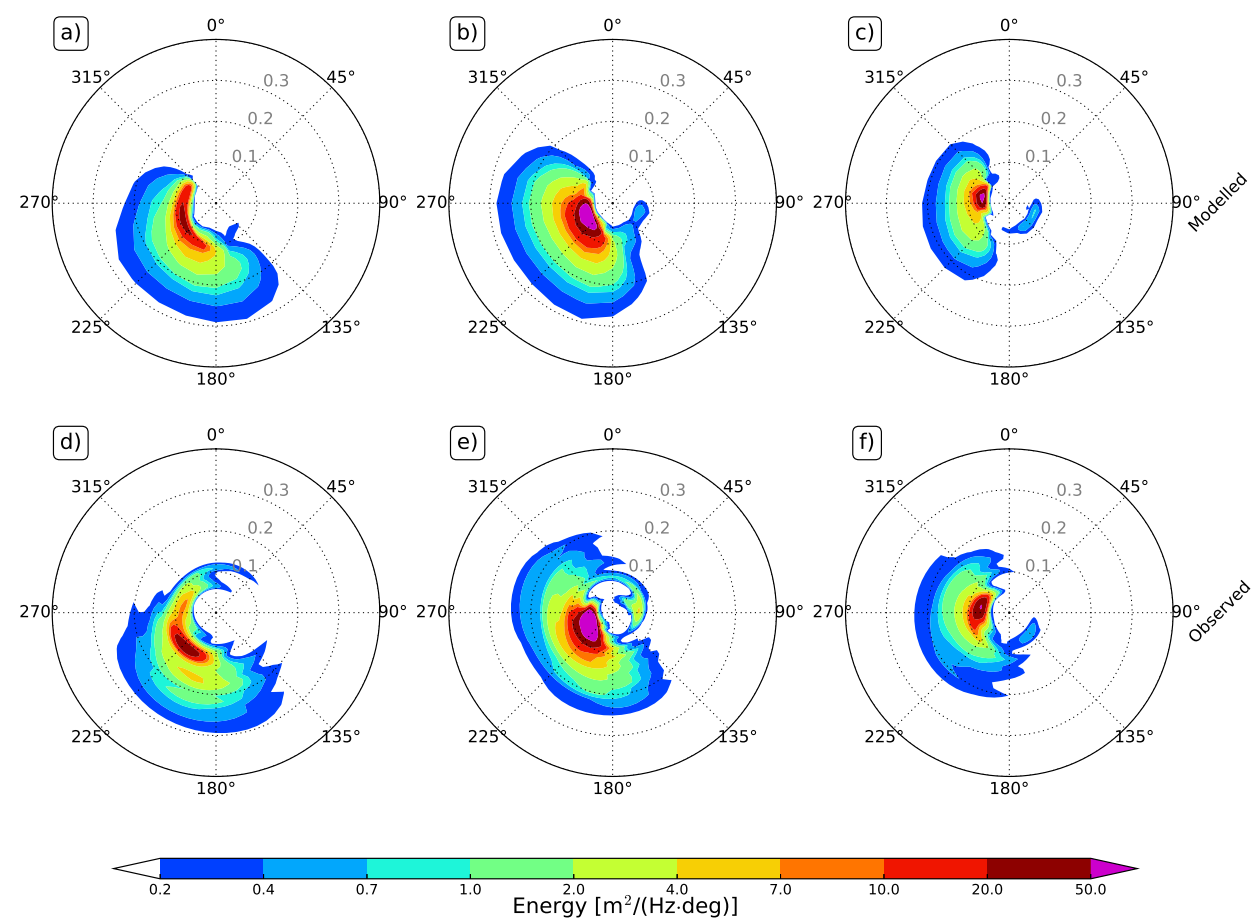

Figure 12: Computed (T471ECMWF) and measured frequency-directional wave spectra at the beginning ( $a$ and $d)$, peak ( $b$ and e) and end (c and $\mathrm{f}$ ) of the storm S10 at buoy 62069 .

system are capable of driving strong westerly winds, as displayed in Figure $16 \mathrm{a}$.

The intense wind forcing in the southern part of the low pressure system controls the wave storm propagation across the Atlantic. Figure 16 highlights the spatial relationship between the low pressure system and the wind and wave height fields as the storm hits the offshore buoy 62163. This Figure displays the results obtained by the Test471ECMWF. The largest winds (in excess of $25 \mathrm{~m} / \mathrm{s}$ ) and significant wave heights (in excess of $10 \mathrm{~m}$ ) are predicted to occur inside the half circle of $800 \mathrm{~km}$ radius depicted in Figure 16.

To assess the model performance along the storm propagation, we retain the $H_{s}$ altimeter measurements falling inside a half-circle of $800 \mathrm{~km}$ of radius 

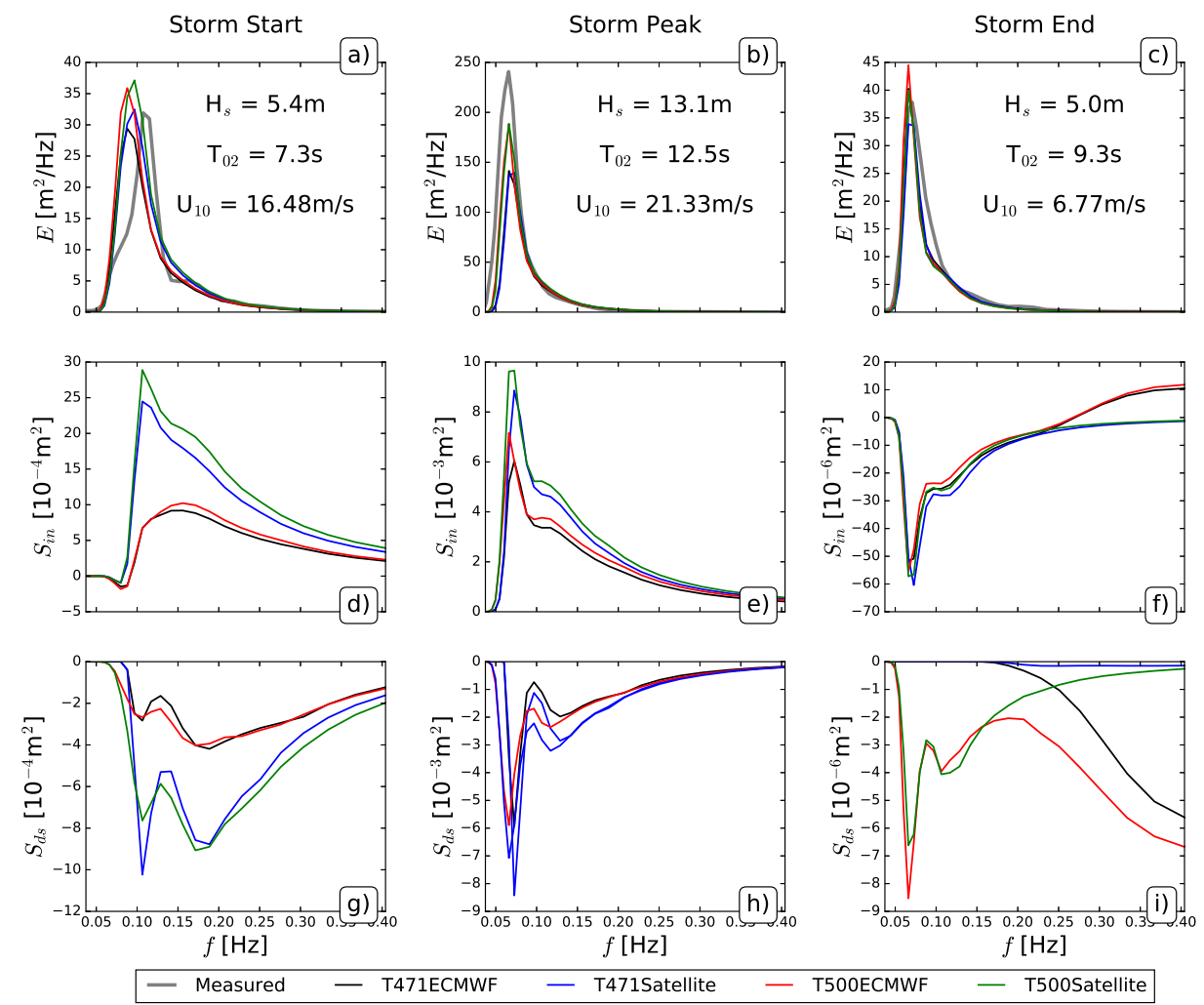

Figure 13: Frequency wave spectra at the beginning (a), peak (b) and end (c) of the storm S10 at buoy 62069 (T471ECMWF). The values of $H_{s}$ and $T_{02}$ are those measured by the buoy; the wind speed at $10 \mathrm{~m} U_{10}$ is from the ECMWF dataset. Atmospheric source terms (d-f). Dissipation source term (g-i).

south of the centre of the recognized low-pressure systems. See Figures 3 and 16. Figure 17 shows the comparison between the $H_{s}$ from altimeter measurements and from model computations along the storm propagation paths. The model results have been interpolated from the regular grid over the altimeter path. The observation of the scatterplots of Figure 17 draws the attention to the combined role played by model forcing and parameterization used. Whereas Test471Satellite and Test500ECMWF are characterized by minimal NBIAS values, Test500Satellite and Test471ECMWF give positive and negative NBIAS values, respectively. Test500ECMWF is the one showing the lowest NRMSE.

Figure 18 compares the wind from the ECMWF and satellite forcing 

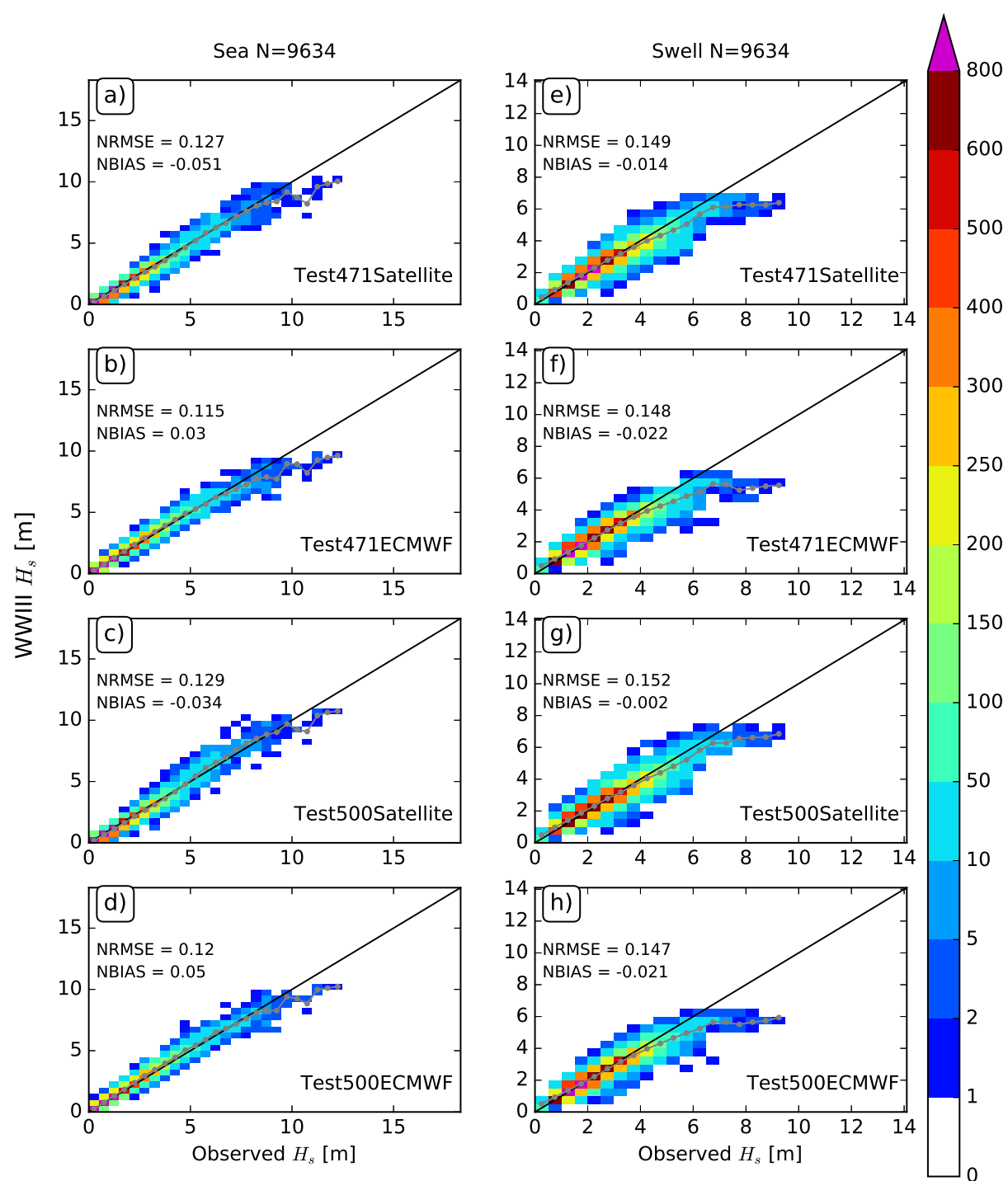

Figure 14: Scatter plot of observed versus modelled significant wave height $H_{s}$ os the sea component (a-d) and the swell component (e-h). The four datasets are shown. The grey line represents the mean of the model values. 
Table 5: Sea and swell waves statistics in coastal water.

\begin{tabular}{ccccccc}
\hline \multirow{2}{*}{ Dataset } & All $\begin{array}{c}\text { Extreme } \\
\text { Wind waves }\end{array}$ & \multicolumn{4}{c}{$\begin{array}{c}H_{s} \text { NRMSE } \\
\text { Swell waves }\end{array}$} \\
\hline T471Satellite & 0.13 & 0.13 & 0.11 & 0.15 & 0.14 & 0.11 \\
T471ECMWF & 0.12 & 0.14 & 0.10 & 0.15 & 0.15 & 0.11 \\
T500Satellite & 0.13 & 0.10 & 0.12 & 0.15 & 0.12 & 0.12 \\
T500ECMWF & 0.12 & 0.10 & 0.12 & 0.15 & 0.13 & 0.13 \\
\hline \multicolumn{7}{c}{$H_{s}$ NBIAS } \\
Dataset & All & Extreme & Storm & All & Extreme & Storm \\
\multicolumn{7}{c}{ Wind waves } \\
T471Satellite & -0.05 & -0.07 & 0.04 & -0.01 & -0.08 & -0.08 \\
T471ECMWF & 0.03 & -0.10 & 0.01 & -0.02 & -0.10 & -0.07 \\
T500Satellite & -0.03 & -0.01 & 0.06 & -0.00 & -0.05 & -0.04 \\
T500ECMWF & 0.05 & -0.06 & 0.03 & -0.02 & -0.08 & -0.04 \\
\hline
\end{tabular}

datasets. The wind speed values are extracted along the low-pressure systems path propagation, thus corresponding to the time and location of $H_{s}$ values of figure 17 . The NBIAS is slightly negative meaning that, along the extra-tropical cyclone paths, the winds of ECMWF forcing are smaller than those of the satellite forcing. This underestimation becomes more evident for strong winds above $20 \mathrm{~m} / \mathrm{s}$. This is consistent with Figure 17, in which for a given parameterization, NBIAS of $H_{s}$ is lower with the adoption of ECMWF forcing. In fact, the smaller ECMWF storm winds are likely to yield lower energy transfer rates from the atmosphere to the wave motion, eventually reducing the sea state growth along storm tracks.

\section{Discussion}

In this work, wave spectral numerical simulations under storm wave conditions show a substantial dependence on the wind forcing and wave dissipation parameterization used. Roland and Ardhuin (2014) suggested that the quality of wind data and source term parameterizations are the main factors defining the accuracy of spectral wave results. Here, we address this subject 


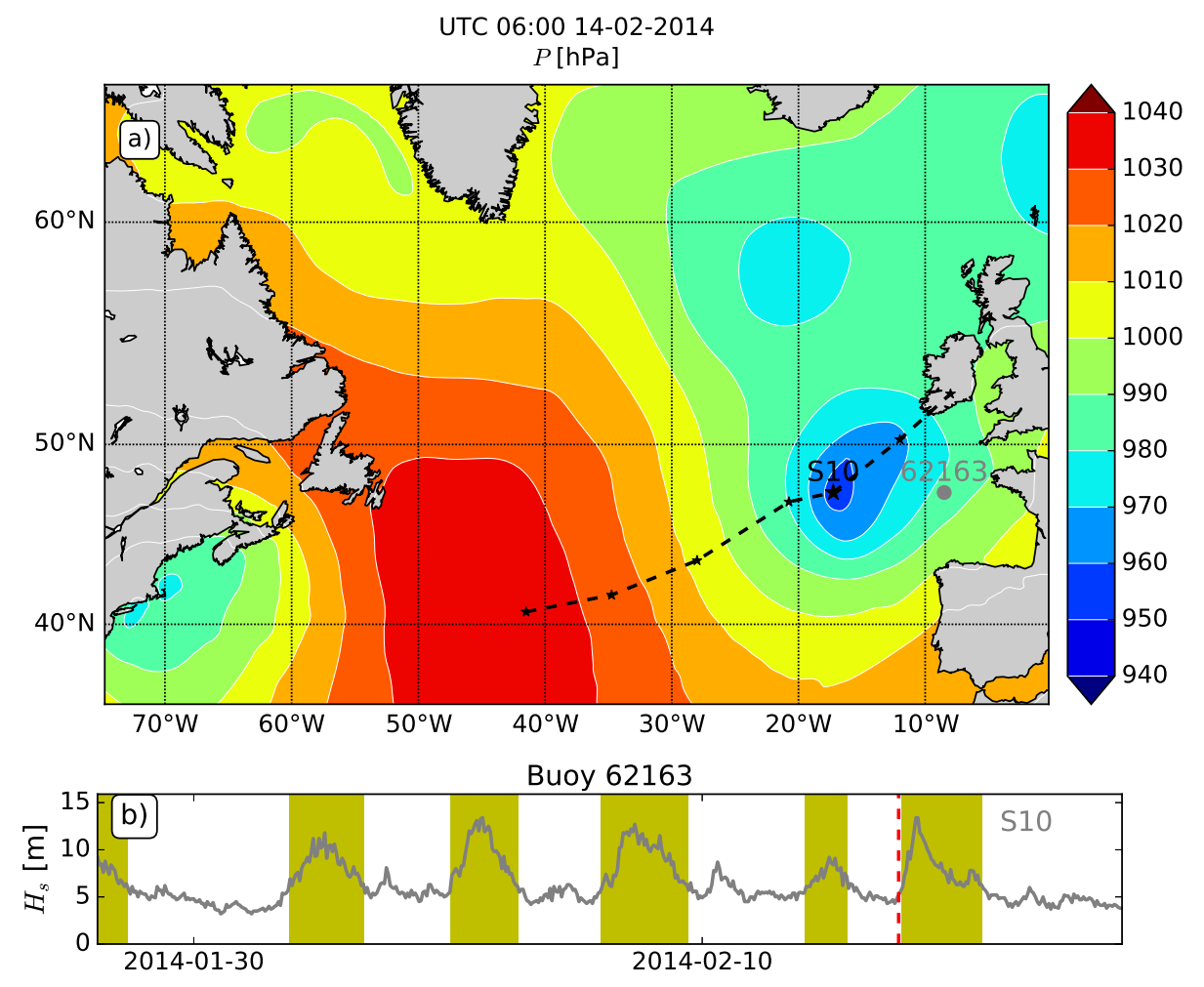

Figure 15: a) Atmospheric pressure field at the moment of the S10 storm arrival at the deep-water buoy 62163 (grey point). The dashed line indicates the low-pressure system path. b) Time series of significant wave height $H_{s}$ recorded at the buoy 62163 . The red dashed line marks the time instant of panel a). The storms at the buoy 62163 are highlighted in yellow.

under extreme storm conditions. This section highlights the main outcomes of the present study and discusses its results in the light of previous work.

A first analysis assesses the model performance separately at deep water buoys and coastal buoys. Model performance decreases when computed data are compared with buoy measurements in coastal water. This result is consistent with previous studies (Ravdas et al., 2018). In contrast with deep water waves, coastal waves are controlled by the combined effect of irregular shorelines, uneven bathymetry and mean water level oscillations. In addition, the interaction with strong tidal currents is not negligible. Besides the challenges in modelling the complex physics of coastal wave processes, the 


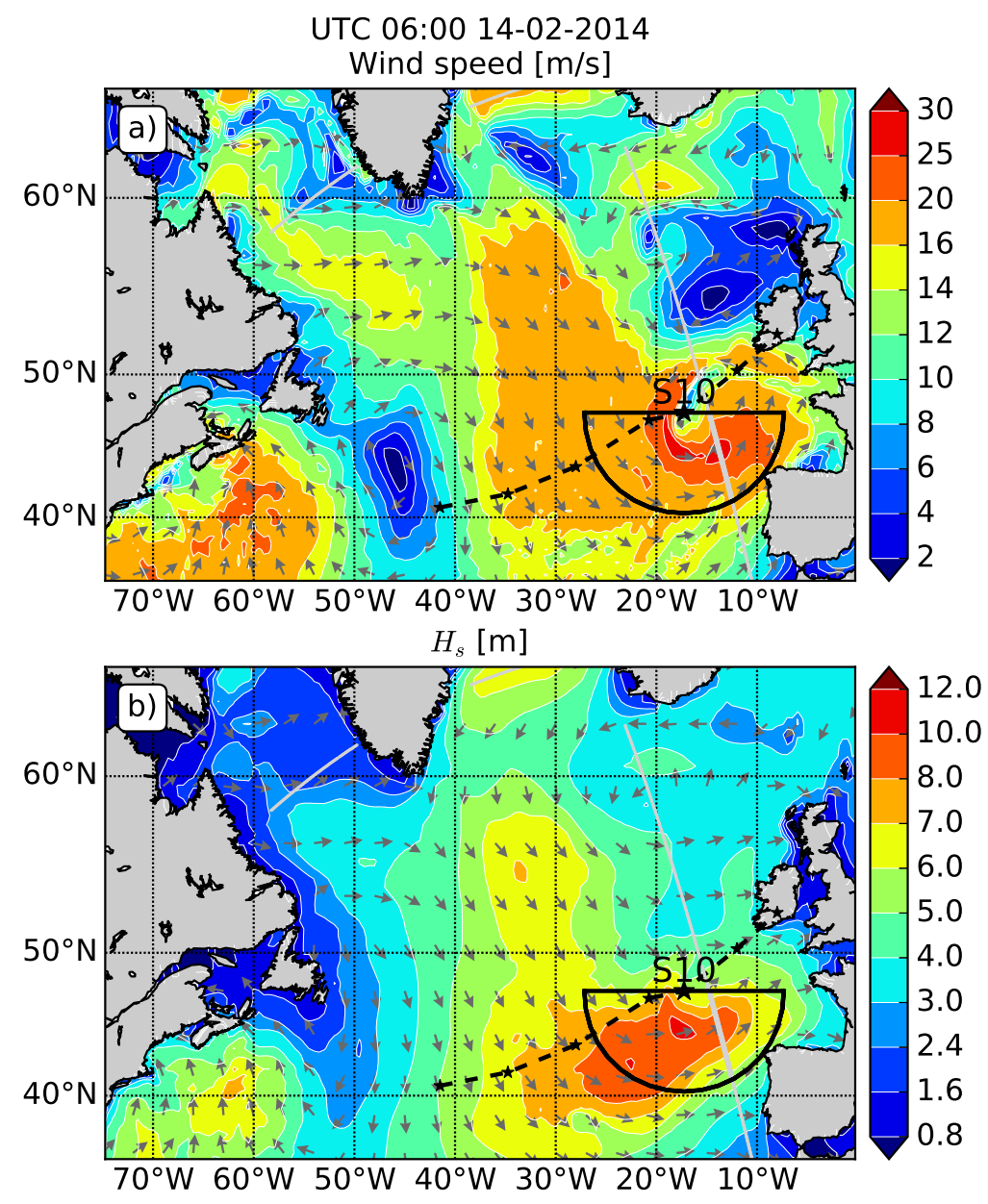

Figure 16: a) Wind speed field at the moment of the S10 storm arrival at the deep-water buoy 62163 . b) Significant wave height $H_{s}$ field at same time of panel a). The dashed line indicates the low-pressure system path. The solid black line shows the half circle with radius of $800 \mathrm{~km}$. Altimeter measurement locations are shown by the grey dots.

quality of bathymetric and ocean circulation data play a significant role. In fact, tidal currents, mean water levels and bathymetry data are inevitably affected by errors that may propagate into the wave model and therefore decrease its accuracy in the nearshore.

The NRMSE and NBIAS values of $H_{s}$ along storm tracks across the Atlantic are consistent with those at deep water buoys during storm duration. 

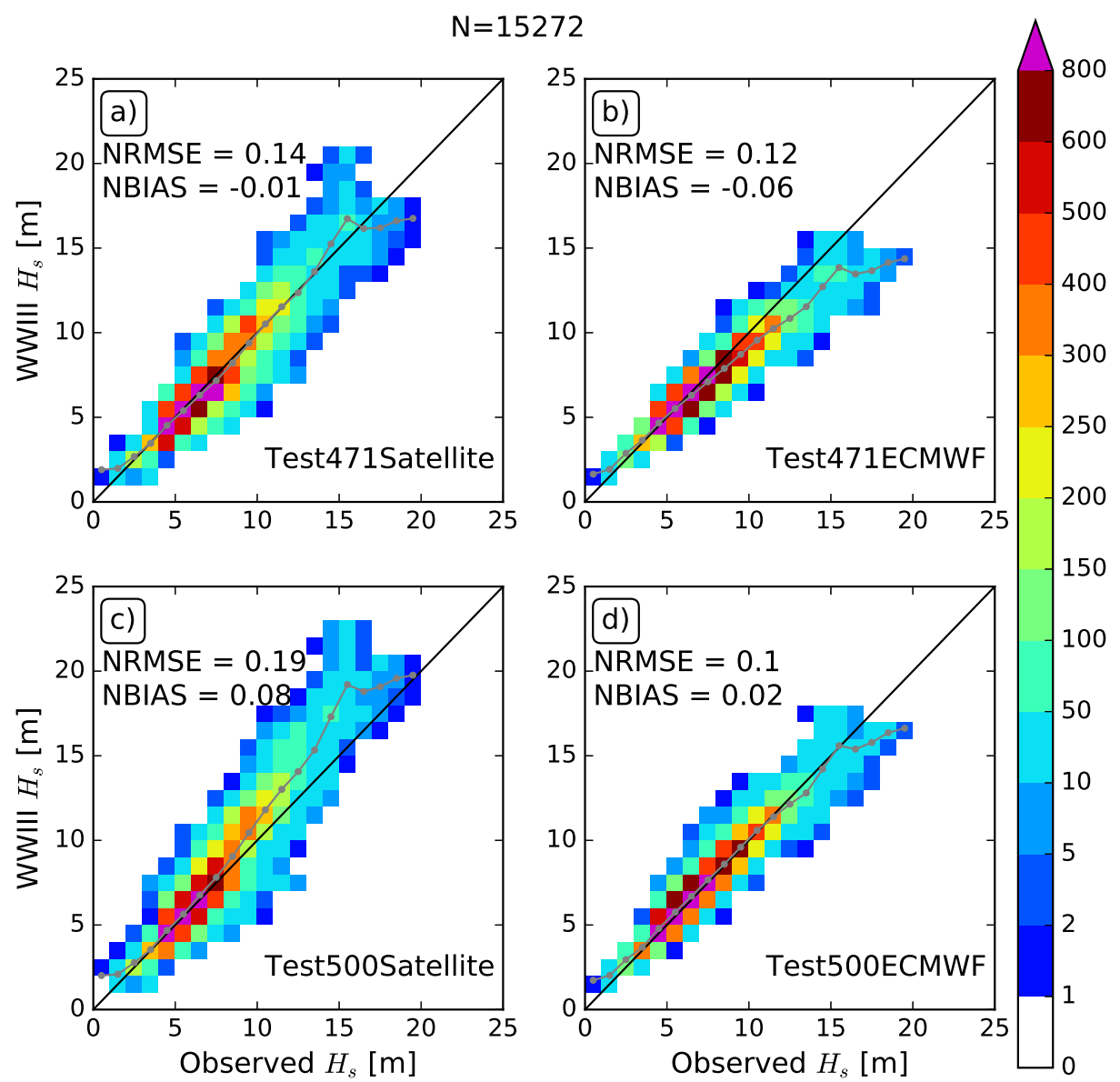

Figure 17: Scatterplots of the observed versus modelled significant wave height $H_{s}$ along the storm tracks. Panels a), b), c) and d) show the comparison for different forcings and parameterizations. The grey line represents the mean of the model values.

For a given parameterization, the use of the wind forcing from satellite data tends to increase the NBIAS with respect to the use of the ECMWF wind forcing. This is likely to be related to an underestimation of extreme winds by the the ECMWF reanalysis dataset (Rascle and Ardhuin, 2013), see Figure 18. Analogously, for a given wind forcing, NBIAS rises when Test500 is used. This result is consistent with Filipot and Ardhuin (2012). In general terms, 


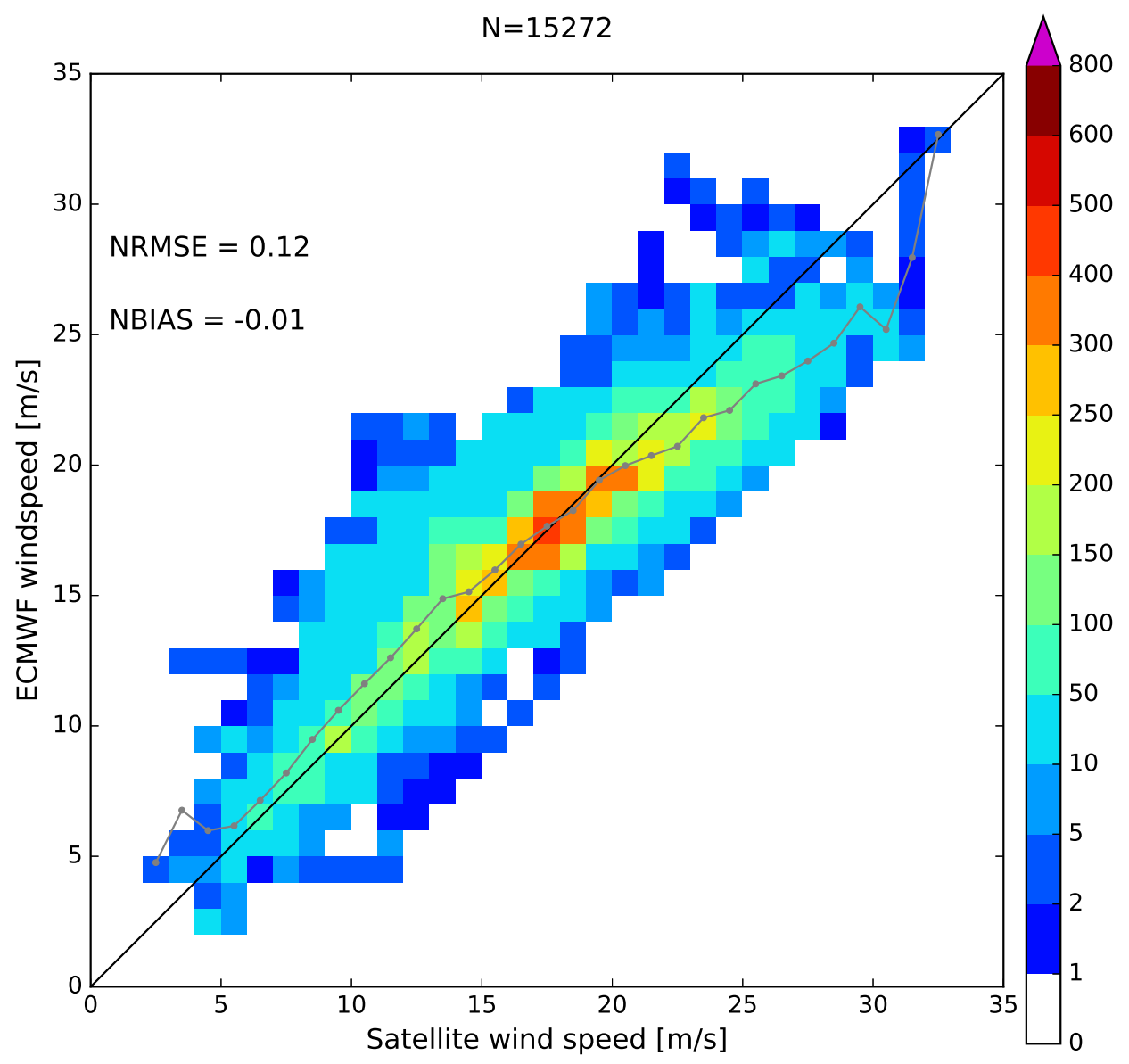

Figure 18: Scatterplot of satellite wind speed versus ECMWF wind speed along the storm tracks. The grey line represents the mean of the model values.

Test500ECMWF seems to be the most robust choice for the simulation of storm evolution both along storm tracks $(\mathrm{NRMSE}=0.1$, NBIAS $=0.02)$ and at buoy locations (NRMSE $=0.1, \mathrm{NBIAS}=-0.01)$.

The spectral analysis shows that all datasets tend to underestimate the swell component oh $H_{s}$ at four coastal buoys during storm conditions. Figure 12 reveals that during an energetic storm a considerable amount of lowfrequency energy is propagating with an opposite direction with respect to 
the main storm direction. This highlights the importance of shallow water processes, such as wave reflection at the shoreline, in determining the total energy budget in coastal water. To have a first assessment of the importance of wave reflection during storms, we isolate the seaward component of spectrum (retaining the seaward wave components that are more than $90^{\circ}$ apart from the main wave direction). The comparison of the $H_{s}$ with the measurements shows that in the model this component is largely underestimated (with NBIAS ranging between -0.19 and -0.25 depending on the dataset). Although the great part of wave energy is propagating shoreward, this strong underestimation of the seaward component of the spectrum is likely to contribute to the underestimation of the swell component under storms in coastal water.

In contrast with its values during storm events, $H_{s}$ at the storm peak is systematically underestimated as revealed by its negative NBIAS values. This result is valid at both offshore and coastal buoys. Although all datasets share this trend, this underestimation is particularly marked using the combination of ECMWF forcing and Test471 parameterization: NBIAS $=-0.15$ and -0.12 in deep and coastal water, respectively. The dataset Test500Satellite provides the smallest NBIAS, in absolute values, thus reducing the underestimation. Although Test500Satellite provides the smallest NRMSE and absolute NBIAS, it seems that it has the main drawback of overestimating $H_{s}$ larger than $15 \mathrm{~m}$ (see Figures 7 and 17).

When comparing the results coming from the different model settings described in this work, it is worth mentioning that the calibration of the two wave breaking parameterizations used here has been carried out with the ECMWF wind forcing (Tolman, 2016). Nevertheless, both parameterizations perform well with satellite forcing showing minimal bias for the entire winter timeseries. Since satellite data are expected to improve the characterization of high wind conditions with respect to the ECMWF products (Bentamy et al., 2017), we argue that a new calibration of parameterizations T471 and T500 with the satellite wind forcing may lead to an improvement of the prediction of extreme sea states. However, the calibration task is beyond the scope of this work, focusing on the winter 2013/2014, as longer simulations are required.

Another aspect to be taken into account is that, as can be seen in Figure 10, $H_{s}$ measurements are more noisy than simulated results. These spikes are likely to enhance the $H_{s}$ peak underestimation by the model that could then be mitigated by applying a despiking filter to the measured timeseries. 
However, we prefer to avoid this alteration due to its involved subjectivity. It can be worth mentioning that Castelle et al. (2015) simply applied a linear coefficient equal to 1.07 to adjust the $H_{s}$ values from WWIII simulations to the measurements from buoy 62064 under the same period.

An underestimation is found also for extreme mean wave period $T_{02}$ and energy flux $F_{e}$ in coastal water. NBIAS for $T_{02}$ is slightly smaller, in absolute value, than that for $H_{s}$. On the other hand, the stronger underestimation of peak values of $F_{e}$ (NBIAS between -0.27 and -0.42) is due to the $F_{e}$ parameter definition, resulting from the product of $E$ which is function of $H_{s}^{2}$ and $c_{g}$ which is function of wave period.

The observed underestimation of extreme wave parameters highlights the importance of the choice of an accurate hindcast product for extreme wave analysis purposes. In fact, long-term hindcasts affected by errors in extreme sea state conditions can strongly impact the the probabilistic moments and the tail of the distributions used for extreme event analysis (Campos et al., 2019). This may have a crucial importance especially in calculation design.

\subsection{Impact of time resolution of forcing winds}

Due to the observed rapid evolution of sea states under extreme weather conditions, it appears plausible that the time resolution of the wind forcing might have an impact on wave model result accuracy. In this paper we have tested two wind datasets with the same time resolution of 6 hours. Here, we assess a possible negative impact of relatively low time resolutions of the wind forcing dataset. The accuracy of the wave output proceeding from simulations with the Test500 parameterization and forced by ECMWF ERA5 winds at one hour resolution is discussed.

In our case the high-resolution wind forcing does not lead to a reduction of the NRMSE of $H_{s}$ for the entire dataset in deep water (NRSME=0.10). The $H_{s}$ data stays unbiased (NBIAS $\left.<0.005\right)$. The main benefit of using a highresolution wind forcing seems to be related to the ability of catching extreme $H_{s}$ at the storm peak. In fact, the NRMSE for extreme $H_{s}$ experiences a small decrease (from 0.111 to 0.106 ). Moreover, the one hour time resolution forcing leads to a smaller underestimation of extreme $H_{s}$ : NBIAS passes from -0.09 to -0.08 . Although detectable, the impact of the time resolution of the forcing winds is undoubtedly limited. The limited magnitude of this improvement seems to be related to the lengthy evolution of Atlantic swells that progressively gain energy along their tracks across the ocean. These swells characterized by a large wave age are likely to dominate the sea state at 
the considered wave buoys, thus reducing the impact of fast wind oscillations included in a high time resolution wind forcing.

What we have observed here in terms of the impact of the increased time resolution of winds on wave modelling is consistent with Mentaschi et al. (2015) who suggested that a resolution increase of the forcing wind field (in their case it was a spatial resolution increase) may not lead to an improvement of single point statistics. According to previous studies (Cavaleri, 2009; Ardhuin et al., 2007; Bertotti and Cavaleri, 2009) they attributed this result to the so-called double penalty effect: some features and patterns may be missed or reproduced in a wrong place in space and time by the model.

\subsection{Parameterization ST6}

Version 5.16 of WWIII includes the new package ST6 which is designed for the parameterization of wind input, wave breaking and swell dissipation. We comment here the results obtained by activating ST6. For our dataset, setting the FAC parameter equal to 1.09, that means increasing the value of the wind drag by $9 \%$, yields a reduction of absolute NBIAS with respect to the default value of $\mathrm{FAC}=1$. This is in agreement with Zieger et al. (2015) who used the same value in combination with CFSR wind reanalysis. In fact, our results shows a clear under- and overestimation of $H_{s}$ with the other two values proposed by Zieger et al. (2015): $\mathrm{FAC}=1$ in combination with $\mathrm{CFS}$ winds and $\mathrm{FAC}=1.23$ in combination with NOGAPS winds. A more detailed sensitivity analysis of the FAC or other parameters included in the parameterization ST6 is beyond the scope of this work.

Although the use of ST6 with $\mathrm{FAC}=1.09$ leads to a small NBIAS for the entire dataset $(<0.04), H_{s}$ values at storm peaks remain underestimated. With both Satellite and ECMWF wind forcing dataset, the use ST6 leads to NBIAS values of extreme (at the storm peak) $H_{s}$ comprised between the values associated with Test471 and Test500. For instance, at deep water buoys with ECMWF forcing, the NBIAS for extreme $H_{s}$ is equal to -0.13 , a value that lies between the those associated with Test471 (-0.15) and Test500 (-0.09), see Table 3 . This results suggest that, despite ineluctable differences, the general behaviour of ST6 in predicting $H_{s}$ under moderate and extreme conditions is analogous to what we have already seen and commented for Test471 and Test500 of the parameterization group ST4. 


\section{Conclusions}

The aim of this work was to assess the impact of wave breaking parameterizations and wind forcing datasets on the accuracy of spectral wave model results under storm wave conditions. We used the WWIII model to simulate the storm sequence occurred in the winter 2013/2014 on the North-East Atlantic. This work focused on two wave breaking parameterizations included in the parameterization group ST4: Test471 and Test500. Moreover, we tested two forcing datasets with six-hour time resolution winds: one based on satellite observations and another based on the ECMWF ERA5 reanalysis. The analysis was carried out firstyl by identifying the individual storms at North-East Atlantic buoy locations and then following the storm tracks across the ocean. The main findings are summarized here:

1. The choice of the combination of the wave breaking parameterization and the wind forcing dataset significantly affects the model results in terms of NBIAS and NRMSE of wave parameters. This is valid for wave parameters computed over the entire time series, during storm evolution as well as at the storm peaks. The change of a given breaking parameterization or wind forcing dataset leads to changes in NBIAS and NRMSE of $H_{s}$ and $T_{02}$ that are on the order of $5 \%$. Due to its definition involving the product between group parameters function of $H_{s}^{2}$ and $T_{02}, F_{e}$ suffers more variability.

2. For a given wave dissipation paremeterization and wind forcing, the NBIAS and NRMSE values of $H_{s}$ computed under storm conditions at wave buoys are consistent with those computed along storm tracks across the Atlantic. Test500 together with the satellite wind forcing gives higher $H_{s}$ values, thus increasing the NBIAS with respect to, respectively, Test471 and ECMWF wind forcing. By improving the error metrics, Test500ECMWF seems to represent the most robust choice for simulating the storm evolution.

3. Negative NBIAS values of $H_{s}$ at the storm peaks reveal a significant underestimation of extreme wave conditions that is particularly marked at the coastal buoy locations. This underestimation, common to all the tested datasets, is reduced by using the Test500Satellite dataset.

4. The spectral analysis shows that at the coastal buoys a considerable amount of energy is propagating seaward during storms, possibly as a result of wave reflection at the shoreline. This seaward component is 
strongly underestimated by the model (NBIAS of the order of -0.2), thus contributing to the underestimation of the swell component at the coastal buoy locations.

5. The use of the high-resolution wind forcing (one-hour resolution) ERA5 does not significantly improve the error statistics computed over the entire time series at the wave buoys. The main benefit of using a high-resolution forcing resides in the (limited, on the order of 1\%) improvement of NRMSE and NBIAS values of extreme wave conditions at storm peaks.

\section{Acknowledgments}

This work was financially supported by the ARCWIND project "Adaptation and implementation of floating wind energy conversion technology for the Atlantic region" (EAPA 344/2016), which is co-financed by the European Regional Development Fund through the Interreg Atlantic Area Programme. Moreover, it benefited from government support managed by the Agence Nationale de la Recherche under the program Investissement d'Avenir with the reference ANR-10-IEED-0006-14 and ANR-10-IEED-0006-26 related to the projects DiMe and CARAVELE.

\section{References}

Ardhuin, F., Bertotti, L., Bidlot, J.R., Cavaleri, L., Filipetto, V., Lefevre, J.M., Wittmann, P., 2007. Comparison of wind and wave measurements and models in the western mediterranean sea. Ocean Engineering 34, 526 - 541. URL: http://www.sciencedirect.com/science/article/pii/S0029801806001193, doi:https://doi.org/10.1016/j.oceaneng.2006.02.008.

Ardhuin, F., Marié, L., Rascle, N., Forget, P., Roland, A., 2009. Observation and estimation of lagrangian, stokes, and eulerian currents induced by wind and waves at the sea surface. Journal of Physical Oceanography 39, 2820-2838. URL: https://doi.org/10.1175/2009JP04169.1, doi:10.1175/2009JPO4169.1, arXiv: https://doi .org/10.1175/2009JP04169.1.

Ardhuin, F., Rogers, E., Babanin, A.V., Filipot, J.F., Magne, R., Roland, A., van der Westhuysen, A., Queffeulou, P., Lefevre, J.M., Aouf, L., Collard, F., 2010. Semiempirical dissipation source functions for ocean waves. part 
i: Definition, calibration, and validation. Journal of Physical Oceanography 40, 1917-1941. URL: https://doi.org/10.1175/2010JP04324.1, doi:10.1175/2010JPO4324.1, arXiv:https://doi .org/10.1175/2010JP04324.1.

Autret, R., Dodet, G., Fichaut, B., Suanez, S., David, L., Leckler, F., Ardhuin, F., Ammann, J., Grandjean, P., Allemand, P., Filipot, J.F., 2016. A comprehensive hydro-geomorphic study of cliff-top storm deposits on banneg island during winter 2013-2014. Marine Geology 382, 37 - 55. URL: http://www.sciencedirect.com/science/article/pii/S0025322716302201, doi:https://doi.org/10.1016/j.margeo.2016.09.014.

Banner, M.L., Babanin, A.V., Young, I.R., 2000. Breaking probability for dominant waves on the sea surface. Journal of Physical Oceanography 30, 3145-3160. URL: https://doi .org/10.1175/1520-0485 (2000) 030<3145: BPFDWO>2.0.CO;2, doi:10.1175/1520-0485(2000)030<3145:BPFDWO $>2.0$.CO;2, arXiv:https://doi .org/10.1175/1520-0485(2000)030<3145:BPFDWO>2.0.CO;2.

Bentamy, A., Grodsky, S.A., Elyouncha, A., Chapron, B., Desbiolles, F., 2017. Homogenization of scatterometer wind retrievals. International Journal of Climatology 37, 870-889. URL: https://rmets.onlinelibrary.wiley.com/doi/abs/10.1002/joc.4746, doi:10.1002/joc.4746, arXiv:https://rmets.onlinelibrary.wiley.com/doi/pdf/10.1002/jc

Bentamy, A., Mouche, A., Grouazel, A., Moujane, A., Mohamed, A.A., 2019. Using sentinel-1a sar wind retrievals for enhancing scatterometer and radiometer regional wind analyses. International Journal of Remote Sensing 40, 11201147. URL: https://doi.org/10.1080/01431161.2018.1524174, doi:10.1080/01431161.2018.1524174, arXiv:https://doi.org/10.1080/01431161.2018.15241

Bernier, N.B., Alves, J.H.G.M., Tolman, H., Chawla, A., Peel, S., Pouliot, B., Bélanger, J.M., Pellerin, P., Lépine, M., Roch, M., 2016. Operational wave prediction system at environment canada: Going global to improve regional forecast skill. Weather and Forecasting 31, 353-370. URL: https://doi .org/10.1175/WAF-D-15-0087.1, doi:10.1175/WAFD-15-0087.1, arXiv:https://doi .org/10.1175/WAF-D-15-0087.1.

Bertotti, L., Cavaleri, L., 2009. Wind and wave predictions in the adriatic sea. Journal of Marine Systems 78, S227 - S234. URL: 
http: //www.sciencedirect.com/science/article/pii/S0924796309001511, doi:https://doi.org/10.1016/j.jmarsys.2009.01.018. coastal Processes: Challenges for Monitoring and Prediction.

Besio, G., Mentaschi, L., Mazzino, A., 2016. Wave energy resource assessment in the mediterranean sea on the basis of a 35-year hindcast. Energy 94, 50 - 63. URL: http://www.sciencedirect.com/science/article/pii/S0360544215014127, doi:https://doi.org/10.1016/j.energy.2015.10.044.

Biscara, L., Schmitt, T., Correard, S., Créach, R., 2014. Modèles numériques de bathymétrie pour la prévision hydrodynamique du dispositif vigilance vagues-submersions, in: Journées Nationales Génie Côtier - Génie Civil, pp. 547-556. doi:10.5150/jngcgc.2014.060.

Boudiere, E., Maisondieu, C., Ardhuin, F., Accensi, M., PineauGuillou, L., Lepesqueur, J., 2013. A suitable metocean hindcast database for the design of marine energy converters. International Journal of Marine Energy 3-4, e40 - e52. URL: http://www.sciencedirect.com/science/article/pii/S2214166913000362, doi:https://doi.org/10.1016/j.ijome.2013.11.010. special Issue Selected Papers - EWTEC2013.

Campos, R., Soares, C.G., Alves, J., Parente, C., Guimaraes, L., 2019. Regional long-term extreme wave analysis using hindcast data from the south atlantic ocean. Ocean Engineering 179, 202 - 212. URL: http://www.sciencedirect.com/science/article/pii/S0029801818318110, doi:https://doi.org/10.1016/j.oceaneng.2019.03.023.

Castelle, B., Marieu, V., Bujan, S., Splinter, K.D., Robinet, A., Senechal, N., Ferreira, S., 2015. Impact of the winter 2013-2014 series of severe western europe storms on a double-barred sandy coast: Beach and dune erosion and megacusp embayments. Geomorphology 238, 135 - 148. URL: http://www.sciencedirect.com/science/article/pii/S0169555X15001385, doi:https://doi.org/10.1016/j.geomorph.2015.03.006.

Cavaleri, L., 2009. Wave modeling-missing the peaks. Journal of Physical Oceanography 39, 27572778. URL: https://doi.org/10.1175/2009JP04067.1, doi:10.1175/2009JPO4067.1, arXiv: https : //doi .org/10.1175/2009JP04067.1. 
Desbiolles, F., Bentamy, A., Blanke, B., Roy, C., Mestas-NuÃez, A.M., Grodsky, S.A., Herbette, S., Cambon, G., Maes, C., 2017. Two decades [1992-2012] of surface wind analyses based on satellite scatterometer observations. Journal of Marine Systems 168, 38 - 56. URL: http://www.sciencedirect.com/science/article/pii/S0924796316302068, doi:https://doi.org/10.1016/j.jmarsys.2017.01.003.

Dodet, G., Bertin, X., Taborda, R., 2010. Wave climate variability in the North-East Atlantic Ocean over the last six decades. Ocean Modelling 31, 120 - 131 . URL: http://www.sciencedirect.com/science/article/pii/S1463500309002066, doi:https://doi.org/10.1016/j.ocemod.2009.10.010.

Filipot, J.F., Ardhuin, F., 2012. A unified spectral parameterization for wave breaking: From the deep ocean to the surf zone. Journal of Geophysical Research: Oceans 117. URL: https://agupubs .onlinelibrary.wiley.com/doi/abs/10.1029/2011JC007784, doi:10.1029/2011JC007784, arXiv:https://agupubs .onlinelibrary.wiley.com/doi/pdf/10

Filipot, J.F., Ardhuin, F., Babanin, A.V., 2010. A unified deep-to-shallow water wave-breaking probability parameterization. Journal of Geophysical Research: Oceans 115. URL: https://agupubs . onlinelibrary.wiley.com/doi/abs/10.1029/2009JC005448, doi:10.1029/2009JC005448, arXiv: https://agupubs . onlinelibrary.wiley.com/doi/pdf/10

Hanson, J.L., Phillips, O.M., 2001. Automated analysis of ocean surface directional wave spectra. Journal of Atmospheric and Oceanic Technology 18, 277-293. URL: https://doi.org/10.1175/1520-0426 (2001) 018<0277:AAOOSD>2 . 0 . CO;2, doi:10.1175/1520-0426(2001)018<0277:AAOOSD $>2.0$.CO;2, arXiv:https://doi .org/10 .1175/1520-0426(2001) 018<0277:AA00SD>2 .0 .CO;2.

Hersbach, H., Bell, W., Berrisford, P., Horányi, A., J., M.S., Nicolas, J., Radu, R., Schepers, D., Simmons, A., Soci, C., Dee, D., 2019. Global reanalysis: goodbye ERA-Interim, hello ERA5 , 17-24URL: https://www.ecmwf.int/node/19027, doi:10.21957/vf291hehd7.

Holthuijsen, L.H., Powell, M.D., Pietrzak, J.D., 2012. Wind and waves in extreme hurricanes. Journal of Geophysical Research: Oceans 117. URL: 
https://agupubs.onlinelibrary.wiley.com/doi/abs/10.1029/2012JC007983, doi:10.1029/2012JC007983, arXiv:https ://agupubs.onlinelibrary.wiley.com/doi/pdf/10

Lazure, P., Dumas, F., 2008. An external-internal mode coupling for a 3D hydrodynamical model for applications at regional scale (MARS). Advances in Water Resources 31, 233 - 250. URL: http://www.sciencedirect.com/science/article/pii/S0309170807001121, doi:https://doi.org/10.1016/j.advwatres.2007.06.010.

Leckler, F., Ardhuin, F., Filipot, J.F., Mironov, A., 2013. Dissipation source terms and whitecap statistics. Ocean Modelling 70, $62-74$. URL: http: //www.sciencedirect.com/science/article/pii/S1463500313000474, doi:https://doi.org/10.1016/j.ocemod.2013.03.007. ocean Surface Waves.

Longuet-Higgins, M.S., 1952. On the statistical distribution of the heights of sea waves. Journal of Marine Research 11, 245-266.

Masselink, G., Scott, T., Poate, T., Russell, P., Davidson, M., Conley, D., 2016. The extreme 2013/2014 winter storms: hydrodynamic forcing and coastal response along the southwest coast of england. Earth Surface Processes and Landforms 41, 378-391. URL: https://onlinelibrary.wiley.com/doi/abs/10.1002/esp.3836, doi:10.1002/esp.3836, arXiv:https://onlinelibrary.wiley.com/doi/pdf/10.1002/esp.383

Mathiesen, M., Goda, Y., Hawkes, P.J., Mansard, E., Martin, M.J., Peltier, E., Thompson, E.F., Vledder, G.V., 1994. Recommended practice for extreme wave analysis. Journal of Hydraulic Research 32, 803-814. URL: https://doi.org/10.1080/00221689409498691, doi:10.1080/00221689409498691, arXiv: https://doi .org/10.1080/00221689409498691.

Mentaschi, L., Besio, G., Cassola, F., Mazzino, A., 2015. Performance evaluation of wavewatch iii in the mediterranean sea. Ocean Modelling 90, $82-94 . \quad$ URL: http://www.sciencedirect.com/science/article/pii/S1463500315000578, doi:https://doi.org/10.1016/j.ocemod.2015.04.003.

Michaud, H., Dalphinet, A., Huchet, M., Pasquet, A., Baraille, R., Leckler, F., Aouf, L., Roland, A., Sikiric, M., Ardhuin, F., Filipot, J.F., 2015. Implementation of the next french operational coastal wave forecasting 
system and application to a wave-current interaction study, in: 14th International Workshop on Wave Hindcasting and Forecasting and 5th Coastal Hazard Symposium.

Miche, A., 1944. Mouvements ondulatoires de la mer en profondeur croissante ou décroissante. Forme limite de la houle lors de son déferlement. Application aux digues maritimes. Troisième partie. Forme et propriétés des houles limites lors du déferlement. Croissance des vitesses vers la rive. Annales des Ponts et Chaussées Tome 114, 369-406.

Mironov, A.S., Dulov, V.A., 2007. Detection of wave breaking using sea surface video records. Measurement Science and Technology 19, 015405. doi:10.1088/0957-0233/19/1/015405.

O'Reilly, W., Olfe, C.B., Thomas, J., Seymour, R., Guza, R., 2016. The california coastal wave monitoring and prediction system. Coastal Engineering 116, $118-132 . \quad$ URL: http: //www.sciencedirect.com/science/article/pii/S0378383916301120, doi:https://doi.org/10.1016/j.coastaleng.2016.06.005.

Perez, J., Menendez, M., Losada, I.J., 2017. Gow2: A global wave hindcast for coastal applications. Coastal Engineering 124, $1-11$. URL: http://www.sciencedirect.com/science/article/pii/S0378383917300443, doi:https://doi.org/10.1016/j.coastaleng.2017.03.005.

Phillips, O.M., 1984. On the response of short ocean wave components at a fixed wavenumber to ocean current variations. Journal of Physical Oceanography 14, 1425-1433. URL: https://doi .org/10.1175/1520-0485(1984)014<1425:OTROSO>2.0.CO;2, doi:10.1175/1520-0485(1984)014<1425:OTROSO >2.0.CO;2, arXiv:https://doi.org/10.1175/1520-0485(1984)014<1425:OTROSO>2.0.CO;2.

Rascle, N., Ardhuin, F., 2013. A global wave parameter database for geophysical applications. part 2: Model validation with improved source term parameterization. Ocean Modelling 70, 174 - 188. URL: http://www.sciencedirect.com/science/article/pii/S1463500312001709, doi:https://doi.org/10.1016/j.ocemod.2012.12.001. ocean Surface Waves.

Ravdas, M., Zacharioudaki, A., Korres, G., 2018. Implementation and validation of a new operational wave forecasting system of the 
mediterranean monitoring and forecasting centre in the framework of the copernicus marine environment monitoring service. Natural Hazards and Earth System Sciences 18, 2675-2695. URL: https ://www . nat-hazards-earth-syst-sci .net/18/2675/2018/, doi:10.5194/nhess-18-2675-2018.

Reguero, B.G., Losada, I.J., Méndez, F.J., 2018. A recent increase in global wave power as a consequence of oceanic warming, in: Nature Communications.

Roland, A., 2009. Development of WWM II: Spectral wave modelling on unstructured meshes. Ph.D. thesis. Technische Universitat Darmstadt. $212 \mathrm{pp}$.

Roland, A., Ardhuin, F., 2014. On the developments of spectral wave models: numerics and parameterizations for the coastal ocean. Ocean Dynamics 64, 833-846. URL: https://doi .org/10.1007/s10236-014-0711-z, doi:10.1007/s10236-014-0711-z.

Ruju, A., Passarella, M., Trogu, D., Buosi, C., Ibba, A., De Muro, S., 2019. An operational wave system within the monitoring program of a mediterranean beach. Journal of Marine Science and Engineering 7. URL: https : / www .mdpi .com/2077-1312/7/2/32, doi:10.3390/jmse7020032.

Sandhya, K., Murty, P., Deshmukh, A.N., Nair, T.B., Shenoi, S., 2018. An operational wave forecasting system for the east coast of india. Estuarine, Coastal and Shelf Science 202, $114-124$. URL: http://www.sciencedirect.com/science/article/pii/S0272771417310417, doi:https://doi.org/10.1016/j.ecss.2017.12.010.

Scott, T., Masselink, G., O'Hare, T., Saulter, A., Poate, T., Russell, P., Davidson, M., Conley, D., 2016. The extreme 2013/2014 winter storms: Beach recovery along the southwest coast of england. Marine Geology 382, 224 - 241. URL: http://www.sciencedirect.com/science/article/pii/S0025322716302766, doi:https://doi.org/10.1016/j.margeo.2016.10.011.

Simmons, A., Uppala, S., Dee, D., Kobayashi, S., 2007. Era-interim: New ecmwf reanalysis products from 1989 onwards , 25-35URL: https ://www .ecmwf . int/node/17713, doi:10.21957/pocnex23c6. 
Stopa, J.E., Ardhuin, F., Babanin, A., Zieger, S., 2016. Comparison and validation of physical wave parameterizations in spectral wave models. Ocean Modelling 103, 2 - 17 . URL: http://www.sciencedirect.com/science/article/pii/S1463500315001614, doi:https://doi.org/10.1016/j.ocemod.2015.09.003. waves and coastal, regional and global processes.

Thornton, E.B., Guza, R.T., 1983. Transformation of wave height distribution. Journal of Geophysical Research: Oceans 88, 5925-5938. URL: https : //agupubs . onlinelibrary . wiley.com/doi/abs/10.1029/JC088iC10p05925, doi:10.1029/JC088iC10p05925, arXiv:https ://agupubs . onlinelibrary.wiley.com/doi/pdf /

Tolman, H.L., 2016. User manual and system documentation of WAVEWATCH III version 5.16. Technical Report. NOAA/NWS/NCEP: 5830 University Research Court, College Park, MD 20740, USA.

Tolman, H.L., Banner, M.L., Kaihatu, J.M., 2013. The nopp operational wave model improvement project. Ocean Modelling 70, 2-10. URL: http://www.sciencedirect.com/science/article/pii/S1463500312001722, doi:https://doi.org/10.1016/j.ocemod.2012.11.011. ocean Surface Waves.

van Vledder, G.P., C. Hulst, S.T., McConochie, J.D., 2016. Source term balance in a severe storm in the southern north sea. Ocean Dynamics 66, 1681-1697. URL: https://doi.org/10.1007/s10236-016-0998-z, doi:10.1007/s10236-016-0998-z.

Wadey, M.P., Haigh, I.D., Brown, J.M., 2014. A century of sea level data and the uk's 2013/14 storm surges: an assessment of extremes and clustering using the newlyn tide gauge record. Ocean Science 10, 1031-1045. URL: https://www.ocean-sci.net/10/1031/2014/, doi:10.5194/os-101031-2014.

Young, I.R., Ribal, A., 2019. Multiplatform evaluation of global trends in wind speed and wave height. Science 364, 548-552. URL: https://science.sciencemag.org/content/364/6440/548, doi:10.1126/science.aav9527, arXiv:https ://science.sciencemag .org/content/364/6440/5

Zieger, S., Babanin, A.V., Rogers, W.E., Young, I.R., 2015. Observation-based source terms in the third-generation wave model wavewatch. Ocean Modelling 96, $2-25 . \quad$ URL: 
http: //www.sciencedirect.com/science/article/pii/S1463500315001237, doi:https://doi.org/10.1016/j.ocemod.2015.07.014. waves and coastal, regional and global processes. 